\title{
Exergy analysis of a diesel engine with Waste Cooking Biodiesel and Triacetin
}

Chukwuka Odibi $^{(1)}$, Meisam Babaie ${ }^{(1)}$, Ali Zare ${ }^{(2)}$, Md. Nurun Nabi ${ }^{(3)}$, Timothy A. Bodisco ${ }^{(2)}$, Richard J. Brown ${ }^{(4)}$

(1) School of Science, Engineering and Environment, University of Salford, Salford, Manchester M5 4WT, United Kingdom

(2) Flow, Aerosol \& Thermal Energy (FATE) Group, School of Engineering, Deakin University, VIC 3216, Australia

(3) Central Queensland University, Perth, WA 6000, Australia

${ }^{(4)}$ Biofuel Engine Research Facility (BERF), Queensland University of Technology (QUT), QLD 4000, Australia

6 Abstract

This study uses the first and second laws of thermodynamics to investigate the effect of oxygenated fuels on the quality and quantity of energy in a turbo-charged, common-rail sixcylinder diesel engine. This work was performed using a range of fuel oxygen content based on diesel, waste cooking biodiesel, and a triacetin. The experimental engine performance and emission data was collected at 12 engine operating modes. Energy and exergy parameters were calculated, and results showed that the use of oxygenated fuels can improve the thermal efficiency leading to lower exhaust energy loss. Waste cooking biodiesel (B100) exhibited the lowest exhaust loss fraction and highest thermal efficiency (up to 6\% higher than diesel). Considering the exergy analysis, lower exhaust temperatures obtained with oxygenated fuels resulted in lower exhaust exergy loss (down to 80\%) and higher exergetic efficiency (up to $10 \%)$. Since the investigated fuels were oxygenated, this study used the oxygen ratio (OR) instead of the equivalence ratio to provide a better understanding of the concept. The OR has increased with decreasing engine load and increasing engine speed. Increasing the OR 
decreased the fuel exergy, exhaust exergy and destruction efficiency. With the use of B100, there was a very high exergy destruction (up to 55\%), which was seen to decrease with the addition of triacetin (down to 29\%).

Keywords: Energy analysis; exergy analysis; waste cooking biodiesel; fuel oxygen content; exergetic efficiency.

\section{INTRODUCTION}

37 The world's energy demand, which is driven by population and economic growth, is continuously increasing, with a 48\% energy growth projection between 2012 and 2040, while fossil fuel has been forecast to meet approximately three-quarters of the total energy demand 40 in 2040 [1]. This growth is potentially problematic, owing to diminishing non-renewable reserves, large-scale environmental degradation in the form of global warming, and atmospheric pollution due to the products of combustion of these fuels. To overcome the challenges posed by fossil fuel, renewable and alternative energy sources are being sought now,

44 more than ever.

45 Biodiesel offers many advantages as an alternative fuel because it is renewable, energy efficient, sulphur free and biodegradable [2,3]. This alternative energy source can satisfy strict emission rules in some applications and can potentially be used in existing diesel engines. However, it performs differently and has different combustion characteristics compared to diesel fuel, and thus, requires analysis from different points of view to fully appraise its utility as an alternative.

50 The chemical and physical properties of the biofuels such as the biodiesel chain are the key parameters on engine performance and emissions $[4,5]$. 
52 The effect of these fuels on engine performance has been mainly considered using the first law of thermodynamics (energy analysis), as it quantitatively evaluates the energy in the process [6]. However, further clarification with the use of the second law of thermodynamics (exergy analysis) can be achieved for the system inefficiencies. Exergy analysis involves the application of exergy concepts, balances and efficiencies to evaluate and improve the system performance. It qualitatively and quantitatively determines losses in a system and locations where they occur as sources of irreversibilities, and provides more accurate information about engine efficiencies [7,8]. This has rekindled interest in the second law of thermodynamics (exergy analysis), as the use of the first law of thermodynamics (energy analysis) only to evaluate engine performance has the limitation of not being able to evaluate some features of energy degradation $[9,10]$.

With the rationale of better understanding the performance and sensitivity of various operating parameters of internal combustion engines when operating with biodiesel, some studies have considered the use of energy and exergy analysis to evaluate engine performance [11-13]. Karthikeyan et al. [14] compared three blends of rice bran biodiesel with pure diesel using energy and exergy analysis. As reported by Cavalcanti et al. [12], engine at higher load with biodiesel blends operates with higher exergetic efficiency. Rakopoulos and Giakoumis [15] used computer analysis to study the energy and exergy performance of a diesel engine operating under transient engine operating conditions, and they revealed how exergy properties vary with different operating parameters. The first and second law analysis of a four-cylinder direct injected diesel engine fuelled with diesel and peanut oil biodiesel blend were considered in another study [16]. Using a Fortran-based code, Jafarmadar and Nemati [17] studied the performance of diesel/biodiesel blends in a homogenous charge compression ignition engine using a three-dimensional model. The exergy analysis showed the improvement of exergy 
performed both energy and exergy analysis on a diesel engine using castor oil biodiesel with a $190 \mathrm{~kW}$ SHENCK engine dyno when operated at full load. From the result of their analysis, the brake thermal efficiency and exergetic efficiency of the $15 \%$ castor oil blend was seen to equal the diesel fuel ( $0 \%$ blend) with low exhaust gas efficiency. A single-cylinder, watercooled diesel engine was tested by Sayin Kul et al. [19] with varying quantities of biodieseldiesel blends containing $5 \%$ bioethanol operated at different speeds. It was seen that the pure diesel fuel had slightly higher thermal and exergetic efficiencies when compared to the biodiesel blend. However, a study by Zare et al. [20] with the engine used in current research showed that using $100 \%$ waste cooking biodiesel increases the thermal efficiency by up to $5 \%$ for the engine used in this study.

Fuel oxygen content has been introduced as an influential factor in engine performance and emissions [20-25]. Song et al. [23] investigated the effect of oxygen content on combustion in single- and multi-cylinder diesel engines using rapeseed biodiesel to vary the oxygen content of the diesel used. From the results obtained, using oxygenated fuel was associated with a subsequent increase in NOx emissions. Effect of the fuel oxygen content on hydrocarbon formation in diesel engine has been studied recently [26]. It was found that in oxygen-rich condition, combustion temperature was the main influencer on the hydrocarbon formation. Jena and Misra [24] used two different biodiesels separately - palm and karanja. The biodiesels had differing oxygen content and they compared the energetic and exergetic efficiencies in a compression ignition engine. The palm biodiesel, which had higher oxygen content, gave a higher thermal efficiency with less associated irreversibility. Given the thermal efficiency as the ratio of the output power to the input energy from the fuel, with the same output power during the test, lower calorific value of the palm biodiesel was reported to be the reason for the

100 higher thermal efficiency of palm biodiesel. It also concluded that better combustion with less 101 irreversibility was possible with a further increase in the oxygen content of the fuel. This is 
seen in a further study by Zare et al. [20], considering the performance and emissions of waste cooking biodiesel blends whose oxygen content was increased with the addition of triacetin. In

104 previous studies with the same engine and fuels, engine performance and emissions (such as

105 NOx and PM) has been reported during modal cycles [22], steady-state and transient operation

$106[21,29]$ and cold start operation [30]. Compared to diesel with no oxygen content, when it 107 comes to alternative fuels in the market, fuel oxygen content will be an important fuel 108 properties which significantly affects the engine performance and emissions. With a reduction

109 in most exhaust emissions and little insight to the exergy analysis in previous studies conducted

110 by this research group, an exergy-based performance analysis can provide insight to the losses 111 associated with the system [27, 28]. As a result, a detailed evaluation of fuel efficiency as well 112 as irreversibility can be developed.

113 To the knowledge of authors, the effect of fuel oxygen content on exergetic parameters of diesel 114 engine performance in such a wide range has not been studied in the past. In this study, the first 115 and second laws of thermodynamics are used to analyse the quantity and quality of energy 116 produced by diesel and biodiesel blends operated at three different engine speeds and four 117 different loads. The experiments aimed to study the increase in the oxygen content of the blends 118 with the use of triacetin, which has a high oxygen content. Performance parameters were 119 analysed, including the power produced by the engine, brake specific fuel consumption (BSFC), 120 brake thermal efficiency (BTE), fuel energy and exergy, exergetic efficiency, exergy 121 destruction heat and exhaust losses, as well as other irreversibilities associated with operating 122 the engine at different loads and speeds, and with different biodiesel blends. These performance 123 parameters were graphically represented to establish the relationships between the 124 aforementioned variables.

125 As the aim of this manuscript is to study the effect of oxygen content on exergy-related parameters, there is no intention to introduce a new fuel/mixture in this study. However, this 
aspect has been analysed on European Stationary Cycle (ESC) and non-road transient cycle

128 (NRTC) in this research group [21, 22] to evaluate the possibility of using such fuels for Euro 129 III engines.

\section{MATERIALS AND METHODS}

2.1 Engine specification, experimental setup and design of experiment

133 The engine used for this experimental study was a turbo-charged, common-rail, six-cylinder

134 after-cooled diesel engine whose specification is shown in Table 1. The engine load was

135 controlled using an electronically controlled water-brake dynamometer which was coupled

136 with this engine.

137 Table 1. Specification of experimental engine setup

\begin{tabular}{ll}
\hline Model & Cummins ISBe220 31 \\
Emission standard & Euro III \\
Cylinders & 6 in-line \\
Aspiration & Turbocharged \\
Capacity & $5.9 \mathrm{~L}$ \\
Compression ratio & $17: 3: 1$ \\
Bore x Stroke & $102 \times 120(\mathrm{~mm})$ \\
Maximum torque & $820 \mathrm{Nm} \mathrm{@} \mathrm{1500} \mathrm{rpm}$ \\
Maximum Power & $162 \mathrm{~kW} \mathrm{2500} \mathrm{rpm}$ \\
Dynamometer type & Hydraulic \\
Fuel injection & High pressure common rail \\
\hline
\end{tabular}

138

139 The schematic diagram for the experimental setup is presented in Fig. 1. A small fraction of

140 diesel exhaust was passed through a HEPA filter and then gas analysers to measure the gaseous

141 emissions. For $\mathrm{CO}_{2}$ and NOx measurement, CAI-600 CO2 and CAI-600 CLD NO/NOx were

142 used in this study. A Testo 350 XL Portable Emissions Analyser was also used to measure HC

143 and $\mathrm{CO}$. The exhaust was passed through a dilution tunnel before measuring the particle

144 emissions. PM measurement was done with DustTrak II Aerosol Monitor 8530 (TSI) While a 
145 SABLE CA-10 was used to measure $\mathrm{CO}_{2}$ for calculating the dilution ratio. Table 2 shows the

146 accuracy of the measurement systems used for this study.

147

148

149

150

151

152

153

154

155

156

157

158

159

160

161

162

163

164 Table 2. The accuracy of instruments 


\begin{tabular}{|c|c|c|c|c|}
\hline Measurement instruments & $\begin{array}{c}\text { Types of } \\
\text { exhaust } \\
\text { gases }\end{array}$ & Range & Accuracy & $\begin{array}{l}\text { Flow rate } \\
\text { (L min-1) }\end{array}$ \\
\hline $\begin{array}{c}\text { CAI-600 CLD } \\
\text { NO/NOxChemiluminescence } \\
\text { (CLD) Photodiode } \\
\text { (thermally stabilized with } \\
\text { Peltier Cooler) }\end{array}$ & $\mathrm{NO} / \mathrm{NOx}$ & $\begin{array}{c}0-1 \text { to } \\
3,000 \mathrm{ppm}\end{array}$ & $\begin{array}{c}\text { RESPONSE TIME: T90 < } 2 \\
\text { Seconds to } 60 \text { Seconds } \\
\text { Adjustable } \\
\text { RESOLUTION }=10 \mathrm{ppb} \\
\text { NO/NOX (Displays } 5 \text { significant } \\
\text { digits) } \\
\text { REPEATABILITY }>0.5 \% \text { of } \\
\text { Full Scale } \\
\text { LINEARITY }>0.5 \% \text { of Full } \\
\text { Scale } \\
\text { NOISE }<1 \% \text { of Full Scale }\end{array}$ & $0.3-3.0$ \\
\hline $\begin{array}{c}\text { CAI-600 CO2 } \\
\text { Non-Dispersive Infrared } \\
\text { (NDIR) }\end{array}$ & $\mathrm{CO} 2$ & $\begin{array}{c}0- \\
1000 / 2000 / \\
3000 \mathrm{ppm}\end{array}$ & $\begin{array}{c}\text { RESPONSE TIME (IR): T90 < } 2 \\
\text { Seconds to } 60 \text { Seconds } \\
\text { Adjustable (Depending on } \\
\text { configuration) } \\
\text { RESOLUTION Displays Five } \\
\text { Significant Digits } \\
\text { REPEATABILITY }>1.0 \% \text { of } \\
\text { Full Scale } \\
\text { LINEARITY }>0.5 \% \text { of Full } \\
\text { Scale } \\
\text { NOISE }<1 \% \text { of Full Scale }\end{array}$ & 0.25 to 2.0 \\
\hline $\begin{array}{l}\text { Sable CA-10 } \\
\text { CO2 Analyser }\end{array}$ & $\mathrm{CO} 2$ & $\begin{array}{c}0-5 \% \\
\text { standard } \\
0-10 \% \\
\text { optional }\end{array}$ & $1 \%$ of reading & $\begin{array}{c}5-500(\mathrm{x} \\
10-3)\end{array}$ \\
\hline $\begin{array}{l}\text { Testo } 350 \text { XL Portable } \\
\text { Emission Analyser }\end{array}$ & $\begin{array}{l}\mathrm{SO} 2 \\
\mathrm{CO} \\
\mathrm{CO} 2 \\
\mathrm{O} 2 \\
\mathrm{NO} \\
\mathrm{NO} 2 \\
\mathrm{HC}\end{array}$ & $\begin{array}{c}0-5000 \\
\mathrm{ppm} \\
0-10,000 \\
\mathrm{ppm} \\
0-\mathrm{CO}_{2} \\
\max \\
0-25 \% \\
0-3000 \\
\mathrm{ppm} \\
0-500 \\
\mathrm{ppm} \\
0-60,000 \\
\mathrm{ppm}\end{array}$ & $\begin{array}{c}5 \% \text { of mv } \\
5 \% \text { of mv } \\
- \\
0.8 \% \text { of } \mathrm{fv} \\
5 \% \text { of mv } \\
5 \mathrm{ppm} \\
60 \mathrm{ppm}\end{array}$ & 1.2 \\
\hline $\begin{array}{c}\text { DustTrakTM II } \\
\text { Aerosol Monitor } 8530 \text { (TSI) }\end{array}$ & $\begin{array}{c}\text { PM1 } \\
\text { PM2.5 } \\
\text { PM10 }\end{array}$ & $\begin{array}{c}0.001- \\
400 \mathrm{mg} \mathrm{m}- \\
3\end{array}$ & $5 \%$ & 3.0 \\
\hline
\end{tabular}

165 

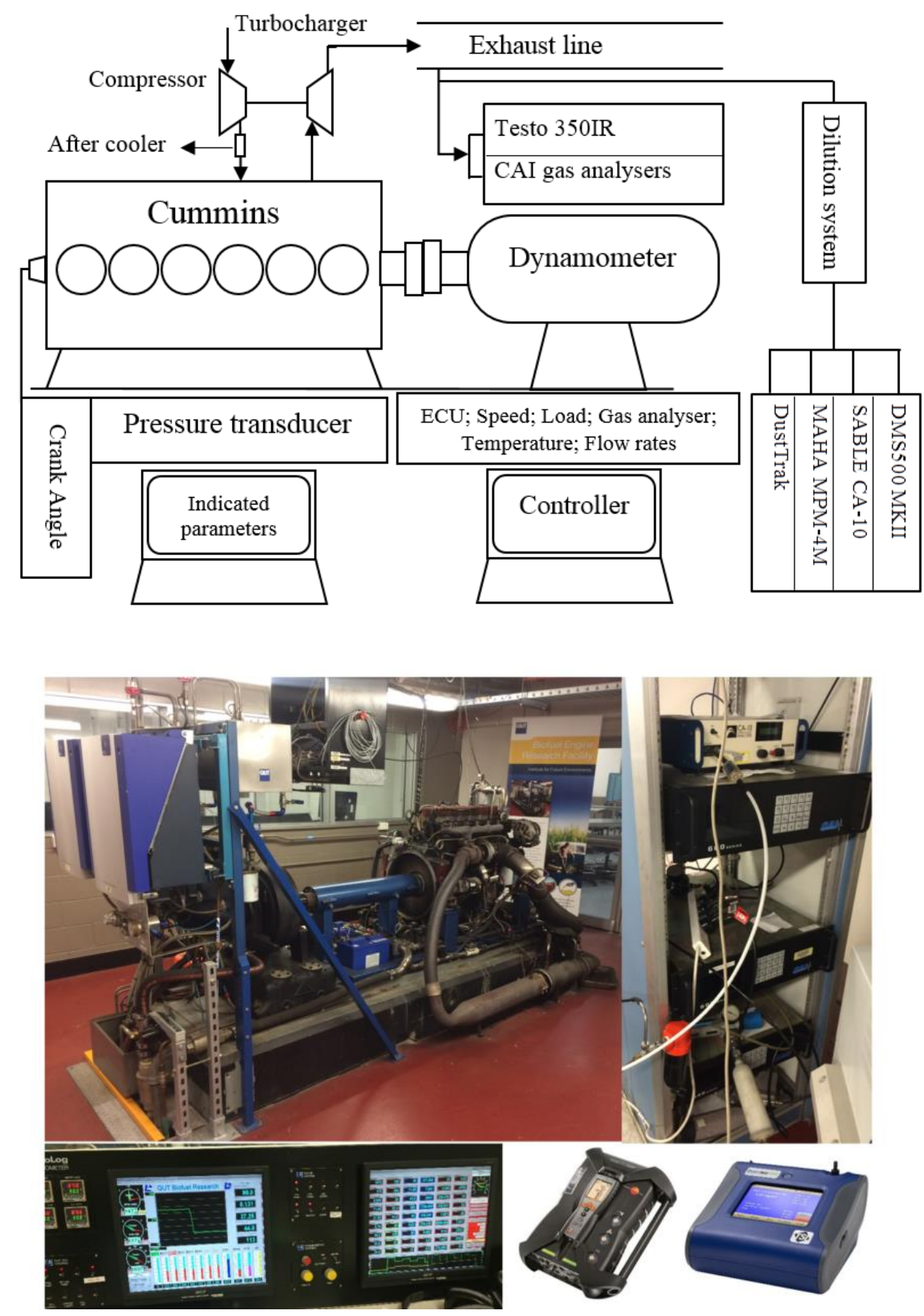

167 Fig. 1. Experimental setup

168

169 Since the engine used in this study was a Euro III engine, the operating modes were selected

170 from the European Stationary Cycle (ESC) schedule. This cycle is a legislated test cycle for

171 heavy-duty engines in the Euro III jurisdiction. In this experiment, 12 engine operating modes 
172 from the ESC comprising three engine speeds (1472, 1865 and $2257 \mathrm{rpm})$ and four engine

173 loads $(25,50,75$ and $100 \%)$ were used.

174

$175 \quad 2.2 \quad$ Fuel properties

176 Diesel (D100), waste cooking biodiesel (B100), and varying proportions of both/either diesel

177 and/or waste cooking biodiesel served as the primary fuel, with triacetin (T). Triacetin was

178 added to waste cooking biodiesel in order to study a wide range of fuel oxygen content. A total

179 of six different fuels were used in this experiment and are denoted by the portion of each fuel

180 in the final fuel, as displayed in the first row of Table 3. For example, T5B35D60 stands for 5\%

181 (by volume) triacetin, 35\% (by volume) biodiesel and 60\% (by volume) diesel. That there was

182 no phase separation as the blends were tested at room temperature for 96 hours to ensure

183 miscibility and stability. It was observed that there was no phase separation. Readers can refer

184 to ref. [20] for more specific information about the fuels used in this study and their effects on

185 engine performance and exhaust emission parameters under different engine operating 186 conditions.

187 It should be noted that beside oxygen, hydrogen and carbon, fuel also contains small trace of

188 sulfur, nitrogen and metals [31]. Our main concern in this investigation was to know the fuel

189 oxygen, as it influences significantly to suppress diesel emissions. We did not account for

190 nitrogen and sulfur to cope up with $100 \%$.

191

192 
194 Table 3. Properties of tested fuels

\begin{tabular}{|c|c|c|c|c|c|c|c|}
\hline Fuel & D100 & T5B35D60 & B100 & T4B96 & T8B92 & T10B90 & $\mathrm{T} 100$ \\
\hline $\mathrm{O}(\mathrm{wt} \%)$ & 0 & 6.02 & 10.93 & 12.25 & 13.57 & 14.23 & 44.00 \\
\hline $\mathrm{C}(\mathrm{wt} \%)$ & 85.1 & 80.46 & 76.93 & 75.81 & 74.73 & 74.19 & 49.53 \\
\hline $\mathrm{H}(\mathrm{wt} \%)$ & 14.8 & 13.47 & 12.21 & 11.97 & 11.74 & 11.63 & 6.42 \\
\hline $\begin{array}{l}\text { Density } \\
@ 15^{\circ} \mathrm{C} \\
(\mathrm{g} / \mathrm{cc})\end{array}$ & 0.84 & 0.866 & 0.87 & 0.882 & 0.893 & 0.898 & 1.159 \\
\hline $\begin{array}{l}\mathrm{HHV} \\
(\mathrm{MJ} / \mathrm{kg})\end{array}$ & 44.79 & 41.74 & 39.9 & 39.02 & 38.15 & 37.72 & 18.08 \\
\hline $\begin{array}{l}\mathrm{LHV} \\
(\mathrm{MJ} / \mathrm{kg})\end{array}$ & 41.77 & 38.92 & 37.2 & 36.38 & 35.57 & 35.16 & 16.78 \\
\hline $\begin{array}{l}\mathrm{KV} @ 40^{\circ} \mathrm{C} \\
\left(\mathrm{mm}^{2} / \mathrm{s}\right)\end{array}$ & 2.64 & 3.66 & 4.82 & 4.94 & 5.06 & 5.12 & 7.83 \\
\hline $\begin{array}{l}\text { Stoichio- } \\
\text { metric air } \\
\left(\mathrm{kg}_{\mathrm{a}} / \mathrm{kg}_{\mathrm{f}}\right)\end{array}$ & 14.89 & 13.64 & 12.59 & 12.33 & 12.07 & 11.94 & 6.02 \\
\hline Formula & $\mathrm{C}_{7.09} \mathrm{H}_{14.8}$ & $\mathrm{C}_{6.71} \mathrm{H}_{13.47} \mathrm{O}_{0.38}$ & $\mathrm{C}_{6.41} \mathrm{H}_{12.21} \mathrm{O}_{0.68}$ & $\mathrm{C}_{6.32} \mathrm{H}_{11.97} \mathrm{O}_{0.77}$ & $\mathrm{C}_{6.23} \mathrm{H}_{11.74} \mathrm{O}_{0.85}$ & $\mathrm{C}_{6.18} \mathrm{H}_{11.63} \mathrm{O}_{0.89}$ & $\mathrm{C}_{9} \mathrm{H}_{14} \mathrm{O}_{6}$ \\
\hline $\mathrm{H} / \mathrm{C}$ & 0.17 & 0.167 & 0.159 & 0.158 & 0.157 & 0.156 & - \\
\hline $\mathrm{O} / \mathrm{C}$ & 0 & 0.0749 & 0.142 & 0.162 & 0.182 & 0.192 & - \\
\hline $\mathrm{S} / \mathrm{C}$ & $<0.1$ & $<0.1$ & $<0.1$ & $<0.1$ & $<0.1$ & $<0.1$ & - \\
\hline
\end{tabular}

195

196 The biodiesel used in this study was provided by Eco Tech Biodiesel Pty Ltd. in Australia.

197 Table 4 shows the fuel technical specification.

198

199

200 
Table 4. Fuel technical specification, Fuel technical specification, Eco Tech Biodiesel,

204 SPECCHECK LABORATORIES P/L, Mittagong, NSW 2575, Australia

\begin{tabular}{|c|c|c|c|c|c|}
\hline METHOD & TEST & RESULT & \multicolumn{2}{|c|}{ SPECIFICTION } & UNITS \\
\hline EN12662 & Total contamination & 11.1 & 24 & $\max$ & $\mathrm{mg} / \mathrm{kg}$ \\
\hline ASTM D664 & Total Acid Number & 0.25 & 0.8 & $\max$ & $\mathrm{mgKOH} / \mathrm{g}$ \\
\hline ASTM D7501 & Cold soak filterability & 201 & 360 & $\max$ & $\mathrm{sec}$ \\
\hline ASTM D874 & Sulphated Ash & $<0.01$ & 0.02 & $\max$ & $\%$ \\
\hline ASTM D4350 & Carbon Residue (10\% res) & 0.108 & 0.3 & $\max$ & $\%$ \\
\hline ASTM D6584 & Free glycerol & 0.01 & 0.02 & $\max$ & $\%$ \\
\hline EN14110 & Alcohol content & 0.02 & 0.2 & $\max$ & $\%$ \\
\hline ASTM D93 & Flash point & $>130$ & 120 & $\min$ & ${ }^{\circ} \mathrm{C}$ \\
\hline ASTM D130 & Copper Corrosion & $1 \mathrm{~A}$ & 1 & $\max$ & - \\
\hline ASTM D6304 & Moisture content & 312 & 500 & & ppm \\
\hline EN14112 & Oxidation stability & 9.52 & 9 & $\min$ & $\mathrm{h}$ \\
\hline EN14103 & Ester content & 97.4 & 96.5 & $\min$ & $\%$ \\
\hline ASTM D6584 & Monoglycerides & 0.246 & 0.8 & $\max$ & $\%$ \\
\hline ASTM D6584 & Total glycerol & 0.089 & 0.25 & $\max$ & $\%$ \\
\hline ASTM D6371 & Cold filter plugging point & -2 & - & - & ${ }^{\circ} \mathrm{C}$ \\
\hline ASTM D2068 & Filter blocking tendency (B100) & 1.05 & 2 & $\max$ & - \\
\hline ASTM D1160 & Distillation temp@90\% rec & 316 & 360 & $\max$ & ${ }^{\circ} \mathrm{C}$ \\
\hline
\end{tabular}

\subsection{Combustion analysis}

207 The number of moles (n) of each individual reactant required for a chemical reaction can be

208 obtained through the knowledge of the mass of the compound set to undergo the reaction. From

209 the knowledge of the moles of the chemical reactant, the reaction equation can be balanced

210 when some of the emission concentrations of individual products have been measured. In this

211 study, the measured emission products found in the emission data include $\mathrm{CO}, \mathrm{O}_{2}, \mathrm{CO}_{2}, \mathrm{HC}$

212 and NO. From these measured compounds, $\mathrm{N}_{2}, \mathrm{H}_{2} \mathrm{O}$, and $\mathrm{H}_{2}$ can be obtained by balancing the

213 chemical equation. Concentrations of other substances such as nitrogen dioxide $\left(\mathrm{NO}_{2}\right)$ and 
214 particulate matter (PM) were sufficiently low compared to others and were neglected in this

215 analysis. The combustion equation can be written as Equation (1):

$216 a C_{\alpha} H_{\beta} O_{\gamma}+b\left(O_{2}+3.76 N_{2}\right) \rightarrow X\left(d O_{2}+e C O_{2}+f C O+j H C+h N O\right)+g H_{2} O+i N_{2}+$

$217 \quad k H_{2}$

218 where the coefficients a, b, d, e, f, g, h, i, j, k are the mole fractions of the respective components

219 and $\mathrm{X}$ is the number of moles of the measured products. It is assumed that no trace of water

220 vapour is contained in the intake air and the calculations assumed that the air was dried, thus

221 the air contains $21 \%$ oxygen and $79 \%$ nitrogen. The coefficients of both the reactant and

222 exhaust product are important in the energy and exergy analysis of the combustion system, as

223 it is needed to carry out further analysis [24]. The values of $\alpha, \beta$ and $\gamma$ are identified from fuel

224 properties as they have been measured and presented in Table 3 for each fuel $(\mathrm{C}, \mathrm{O}$ and $\mathrm{H}$

$225(\mathrm{wt} \%))$. Air and fuel flow rates are available from experimental data, so "a" and "b" are known.

226 Emission concentrations in exhaust are also measured experimentally and the remaining

227 coefficients has been calculated using experimental emission data and material balance from

228 the combustion equation.

$230 \quad 2.4 \quad$ Oxygen ratio

231 The equivalence ratio has been a more widely-used term to show the ratio of fuel and air to that

232 of its stoichiometric ratio. This may be misleading in the case of oxygenated fuels, which have

233 oxygen molecules in their chemical formulae. Pham et al. [32] considered the use of an

234 equivalent parameter to the equivalence ratio termed the oxygen ratio (OR). This is because

235 OR gives a more appropriate measure of stoichiometry for oxygenated fuels. OR which

236 considers the oxygen content in fuel is defined as the ratio of total atoms in the mixture to the

237 total required oxygen atoms for the stoichiometric combustion and is given by Equation (2): 
240 where $O_{2, \text { fuel }}$ and $O_{2, \text { air }}$ are the masses of oxygen in the fuel and intake air ,respectively.

241 Therefore OR changes during the experiment by changing the engine load and speed as under

242 different engine operating condition, the intake air amount is different.

$243 \quad 2.5 \quad$ Energy analysis

244 For the energy analysis to be carried out, some simplifying assumptions are made [33]:

$>$ The entire engine, which excludes the dynamometer, is considered to be a control volume running at steady-state.

The combustion air and exhaust gas each form ideal gas mixtures.

Changes in the potential and kinetic energy of the air, fuel and exhaust gases are negligible.

$>$ The lower heating value (LHV) of the fuel is used due to the vapour state of water in the exhaust product.

252 With the aforementioned assumptions, the fuel input energy rate $\left(\mathrm{Q}_{\mathrm{f}}\right)$ into the control volume 253 is given by Equation (3):

$$
\dot{Q}_{f}=m_{f} \cdot L H V
$$

where $\dot{m}_{f}$ and LHV are the mass flow rate $(\mathrm{kg} / \mathrm{s})$ and the lower heating value $(\mathrm{kJ} / \mathrm{kg})$ of the fuel respectively.

257 The brake power $(\dot{W})$ generated by the engine can be obtained from the engine torque (T) and speed $(\mathrm{N})$ as shown in Equation (4): 


$$
\dot{W}=\frac{2 \pi N T}{60}(\mathrm{~kW})
$$

261 where $\mathrm{N}$ is in rpm and $\mathrm{T}$ is in $\mathrm{kNm}$. The mass and energy balance for the control volume can 262 be represented by the continuity equation and the first law of thermodynamics [33]. The mass 263 balance which equates the mass inflow to the mass outflow is represented in Equation (5):

$$
\sum m_{i}=\sum m_{e}
$$

The energy balance is given in Equation (6) using the brake power from Equation (4).

$$
h_{p}=\sum_{p} n_{e}\left(h_{f}^{0}+\Delta \bar{h}\right)_{e}, \quad h_{R}=\sum_{R} n_{i}\left(h_{f}^{0}+\Delta \bar{h}\right)_{i}
$$

where subscripts $p, R, c v, i$ and $e$ represent the product, reactant, control volume, inlet and exit states, respectively. $n$ denotes the number of moles while $h_{f}^{0}$ and $\Delta h$ represent the standard enthalpy of formation and enthalpy change due to a change of state. Standard Tables of thermodynamic [34] properties are used to extract the standard enthalpy and the enthalpy change at the exit temperature of the gases. To obtain the enthalpy of the reactant $\left(h_{R}\right)$, the

273 formation enthalpy is determined from complete combustion of the fuel when the theoretical

274 quantity of air is supplied [18]. This is mathematically stated as shown in Equation (7):

$$
C_{x} H_{y} O_{z}+\left(x+\frac{y}{4}-\frac{z}{2}\right)\left(O_{2}+3.76 N_{2}\right) \rightarrow x C_{2}+\frac{y}{2} H_{2} O+3.76\left(x+\frac{y}{4}-\frac{z}{2}\right) N_{2}
$$

276 The standard enthalpy of formation for the fuel can be obtained utilising the first law of 277 thermodynamics; the heat released from the reaction equals the lower heating value of the fuel. 278 The enthalpy of the fuel can be obtained from Equation (8):

$$
\left(h_{f}^{o}\right)_{\text {Fuel }}=x\left(h_{f}^{o}\right)_{\mathrm{CO}_{2}}+0.5 y\left(h_{f}^{o}\right)_{\mathrm{H}_{2} \mathrm{O}}+(3.76 x+0.94 y-1.88 z)\left(h_{f}^{o}\right)_{N_{2}}+\overline{L H V}
$$


280 The heat loss through the exhaust gases can be calculated as the difference between the energy

281 input rate from the air/fuel mixture and the control volume, which consists of the mechanical

282 work (brake power) and the heat transfer. The amount of energy brought into the system by the

283 combustion air can be ignored, as it enters the system having the same temperature as the

284 reference environment. The heat loss through the exhaust is mathematically represented as

285 shown in Equation (9):

286

$$
\dot{Q}_{e x h}=\dot{m}_{f} \cdot L H V-\left(\dot{W}+\left|\dot{Q}_{C V}\right|\right)
$$

287 To evaluate how well the engine converts heat to work, the brake thermal efficiency (BTE) is

288 introduced, and is the ratio of the brake power $\dot{w}$ to the fuel energy input rate $\dot{Q}_{f}$, as shown in 289 Equation (10):

$$
B T E=\frac{\dot{W}}{\dot{Q}_{f}}
$$

291 Another important engine characteristic is the brake specific fuel consumption (BSFC), which

292 is a measure of the amount of fuel needed to produce a kilowatt of power in one hour, and it is 293 given by Equation (11):

$$
B S F C=\frac{\dot{m}_{f}}{\dot{W}} 3600
$$

$297 \quad 2.6 \quad$ Exergy analysis

298 In order to effectively carry out the exergy analysis, assumptions used in energy analysis are

299 still valid. The reference environment in this study corresponds to an environment temperature

$300\left(\mathrm{~T}_{0}\right)$ of $298.15 \mathrm{~K}$ and atmospheric pressure of 1 bar. Based on this assumption, the exergy

301 balance for the control volume can be stated as Equation (12): 
303 where $\dot{E}_{Q}$ is the exergy flow rate accompanying the heat leaving the control volume to the

304 environment through the cooling water; $\dot{E}_{W}$ is the exergy flow accompanying work, $\dot{E}_{\text {dest }}$ is 305 the exergy destruction rate due to irreversibility in the control volume; also, $306 \sum \dot{m}_{\text {in }} e_{\text {in }}$ and $\sum \dot{m}_{\text {out }} e_{\text {out }}$ represent the rate of exergy entering and leaving the control 307 volume. $e_{i n}$, and $e_{\text {out }}$ are the specific exergies of the fuel and exhaust gases, and $\dot{m}_{\text {in }}$ and $\dot{m}_{\text {out }}$ 308 are the mass/molar flow rate of the fuel and exhaust gases.

309 The exergy flow rate leaving the control volume through the cooling water can be represented as shown in Equation (13):

$$
\dot{E}_{Q}=\sum Q_{c v}\left(1-\frac{T_{o}}{T_{c w}}\right)
$$

312 Where $Q_{c v}$ is the heat leaving the control volume through the engine cooling water, $T_{o}$ and $T_{c w}$

313 are the temperatures of the reference environment and the cooling water respectively. Also, the

314 exergy associated with the work transfer for the defined control volume is equal to the brake power. It is mathematically represented as shown in Equation (14):

$$
\dot{E}_{W}=\dot{W}
$$

318 The input exergy rate, which is the rate of exergy entering the control volume, can be

319 represented with the chemical exergies of the fuel and combustion air, which can be neglected 320 due to the air entering the engine at the temperature of the reference environment. The input 321 exergy rate can be represented as shown in Equation (15):

$$
\sum \dot{m}_{i n} e_{i n}=\dot{m}_{f} \phi|L H V|
$$


where $\dot{m}_{f}$ is the mass of fuel consumed, and $\phi$ is the chemical exergy factor of the fuel in unit mass as given in Equation (16) [35]:

$$
\phi=\left[1.0401+0.1728 \frac{h}{c}+0.0432 \frac{o}{c}+0.2169 \frac{s}{c}\left(1-2.0628 \frac{h}{c}\right)\right]
$$

where $h, c, o$, and $s$ are the mass fractions of hydrogen, carbon, oxygen and sulphur contents of the fuels from Table 3. The chemical exergy of liquid fuel, is related to its LHV by using an empirical coefficient $(\phi)$ calculated based on atomic compositions [36, 37].

The exhaust gas exergy, which is the rate of exergy leaving the control volume, can be represented by the sum of two constituents: thermomechanical $\left(\overline{\bar{e}}_{t m}\right)$ and chemical $\left(\overline{\bar{e}}_{t h}\right)$ exergies of the fuel. The exhaust gas exergy is represented by Kotas [35] as shown in Equations 17 and 18:

$$
\begin{gathered}
\sum \dot{m}_{o u t} e=n_{f}\left(\overline{\bar{e}}_{t m}+\overline{\bar{e}}_{t h}\right) \\
\overline{\bar{e}}_{t m}=\sum_{i} a_{i}\left[\bar{h}_{i, T}-\bar{h}_{i, T_{O}}-T_{O}\left(\bar{s}_{i, T}^{O}-\bar{s}_{i, T_{O}}^{O}\right)\right]+\bar{R} T_{O} \operatorname{In} \frac{P}{P_{o}} \\
\overline{\bar{e}}_{c h}=\bar{R} T_{O} \sum_{i} a_{i}\left(\ln \frac{y_{i}}{y_{i, 00}}\right)
\end{gathered}
$$

where $\mathrm{h}$ and s are the specific enthalpy and absolute entropy of the exhaust gases, $\mathrm{n}$ is the molar flow rate, $\mathrm{R}$ is the general gas constant, To is the temperature of the reference environment, $\mathrm{p}$ and po are the exhaust gas pressure and reference pressure, $y_{i}$ is the molar fraction of the exhaust gas component $\mathrm{i}$, and $y_{i, 00}$ is the molar fraction of gases in the reference environment tabulated below. The mole fractions are obtained by balancing the chemical equation of each combustion process. In addition, the exhaust gas pressure is considered to be the same as the atmospheric pressure as it is discharged to the environment, thus causing the pressure term of the thermomechanical exergy to equate to zero. Thermophysical properties of gases can be obtained from [34]. Experimental data (such as air and fuel mass flow rates, emission data etc.) 
which varies for each operating condition is used to find the component coefficients in the combustion equation and used with exhaust temperature for each operating condition to obtain

347 the exergy from Eq. 17 and 18.

Table 5: Definition of Environment [38]

\begin{tabular}{ll}
\hline Reference environment & Mole fraction \\
\hline $\mathrm{O}_{2}$ & 20.35 \\
$\mathrm{CO}$ & 0.0007 \\
$\mathrm{CO}_{2}$ & 0.0345 \\
$\mathrm{Others}$ & 0.91455 \\
$\mathrm{H} 2 \mathrm{O}$ & 3.03 \\
$\mathrm{~N}_{2}$ & 75.67 \\
$\mathrm{SO}_{2}$ & 0.0002 \\
$\mathrm{H}_{2}$ & 0.00005 \\
\hline
\end{tabular}

349

350 From Equations 12-18, the irreversibility associated with the combustion process can be 351 obtained. If the exergy balance equation is rearranged (Equation 12), the exergy destruction 352 can be mathematically stated as:

$$
\dot{E}_{\text {dest }}=\sum \dot{m}_{\text {in }} \varepsilon_{\text {in }}-\dot{E}_{Q}-\dot{E}_{W}-\sum \dot{m}_{\text {out }} \varepsilon_{\text {out }}
$$

354 The ratio of each of the exergy components to the input exergy rate is an important indication of exergy analysis, as it shows the fraction of the fuel exergy carried away through the different processes. These fractions obtained from the combustion of a particular fuel can be compared with similar fractions obtained from the combustion of a different fuel whose heating value varies from the other fuel. In order to determine the fraction of the fuel exergy converted to work, second law efficiency is considered. Second law efficiency (also known as exergetic

360 efficiency) is the fraction of the fuel exergy converted to the desired product (work), and is mathematically stated in Equation (20):

$$
\eta_{i i}=\frac{\dot{E}_{w}}{\dot{E}_{f}}=\frac{\dot{E}_{W}}{\dot{m}_{f} e_{f}^{c h}}
$$




\section{RESULTS AND DISCUSSION}

364 In this section, parameters such as brake specific fuel consumption, thermal efficiency, fuel 365 energy and heat loss, as well as the exergetic efficiency and the exergy loss accompanying the 366 exhaust gas are presented. In all figures, the six fuels are differentiated by using different 367 colours; the three engine speeds are shown with three different shapes, and four engine loads are displayed with four shape sizes (the higher the load, the bigger the shape size). For the exergy analysis, the exergy parameters are analysed according to engine operation parameters, i.e. the exergy content of the fuel (fuel exergy) converted to work (brake power), and losses through the exhaust (exhaust exergy) or destruction due to the irreversibilities (exergy destruction). Relationships between energy and exergy parameters were also discussed in details

\subsection{Energy analysis}

376 As the main objective of this work is to look at the exergy parameters, just two main parameters of energy analysis (i.e., BTE and exhaust loss) which are more relevant to exergy analysis will be presented firstly. From the experimental data, brake thermal efficiency (BTE) was obtained and presented in Fig. 2. BTE is a good indicator of how well the chemical energy of the fuel is transformed into useful work as it depends on the brake power, heating value and mass of fuel. From Fig. 2, it is seen that with increasing load, BTE increases. In this study, by increasing the speed, the BTE is seen to be decreased. Considering the variation in BTE among fuels, it is seen that the BTE is higher for B100 in this study, which shows a different trend to the literature. This higher thermal efficiency is a good indication that higher energy input in the form of heat is converted to work. However, it will be discussed further in exergy analysis. It is seen that using oxygenated fuels improves the thermal efficiency when compared with diesel fuel. Improved combustion owing to better mixture formation with oxygen-rich fuels and lower 
exhaust temperatures [39]. The lower exhaust temperature with the oxygenated fuels could be due to the lower calorific value of the fuels, which leads to lower in-cylinder pressure and temperature.

391 Heat loss through the exhaust discharge $t$ is one of the greatest sources of inefficiency. Exhaust 392 energy loss can be looked at as the ratio of the exhaust energy to the fuel input energy to 393 indicate the proportion of the fuel energy carried away by the exhaust gases as presented in Fig. 2. At low loads and high RPMs, over $40 \%$ of the fuel energy is wasted by exhaust discharge. It is seen that increasing the load reduces the proportion of fuel energy carried away by the exhaust gas. The decrease in the proportion of fuel energy carried out by the exhaust gas at full load shows that more energy has been converted to work (causing an increase in BTE), with a slight increase in heat transfer loss. Also, an increase in exhaust energy loss is observed as the speed increases. Considering the fuels, it is observed that the highest proportion of fuel energy wasted as the exhaust gas is for D100 at all operating modes, while B100 had the least exhaust energy loss. This high/low exhaust loss causes a corresponding decrease/increase in other energy forms to which the fuel energy is converted.

From Fig. 2, it is seen that operating the engine at low speed and high load yields higher BTE and lower exhaust energy loss, with B100 having the highest BTE and lowest exhaust energy loss. This indicates a better energy-to-work conversion at high load. Also, it is seen that the values obtained when the engine is operated at $75 \%$ and $100 \%$ load at $1472 \mathrm{rpm}$ are almost the same for the exhaust loss and brake thermal efficiency showing the same order of energy converted to useful work is wasted by exhaust discharge. It is worth noting that increasing the speed at constant load reduces the brake thermal efficiency and heat transfer rate, with a corresponding increase in the proportion of the fuel energy leaving the combustion chamber as

411 exhaust gas. This is true as the increase in speed increases the amount of fuel taken into the combustion chamber, resulting in improper mixing and incomplete combustion. 


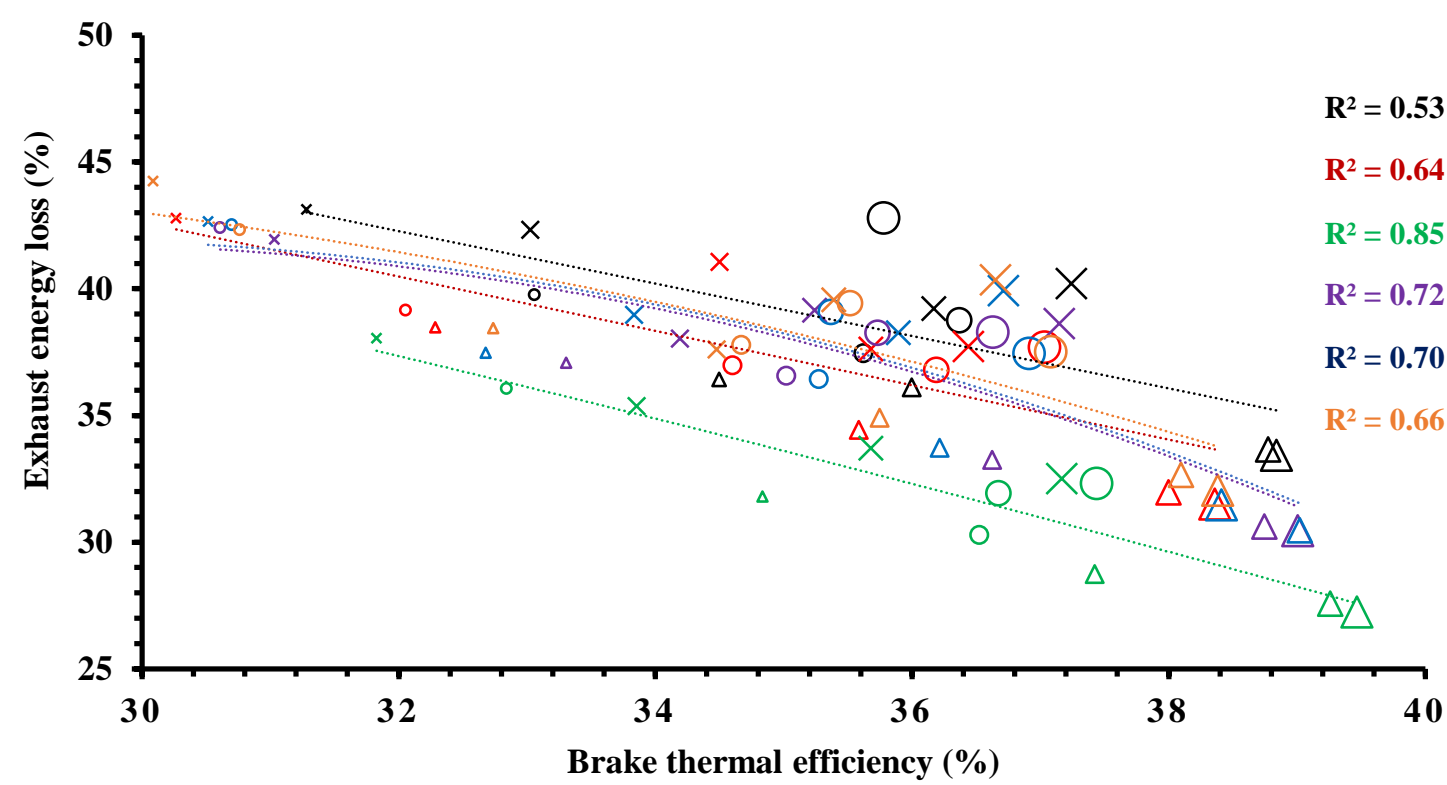

415

416

417

418

419

420

421

422

423

424

425

426

427

428

429

Fig. 2: Exhaust energy loss vs. brake thermal efficiency at 12 engine operating modes for the 6 tested fuels

\subsection{Exergy analysis}

From the second law of thermodynamics, the fuel exergy converted to work is calculated for different fuels and engine operating conditions. Unlike fuel energy, fuel exergy does not only depend on the mass and heating value of the fuel, but also on the chemical exergy factor of the fuel (Equation 15) [19]. From Table 3, it is seen that LHV decreases with an increase in the oxygen content of the fuel, thus causing a decrease in fuel exergy among oxygenated fuels. D100, which has no oxygen content, is expected to have the highest fuel exergy at all operating modes, while T10B90, with the highest oxygen content, should present the least fuel exergy.

Regarding the effect of engine operating condition on exergy and energy analyses, the air-fuel and equivalence ratio can be used. However, these two parameters cannot consider the effect of fuel oxygen content when oxygenated fuels are used, especially given that the fuel oxygen 
430 content has a significant effect on engine performance and emissions [20, 22-24]. Therefore, it

431 is more representative to consider the OR in this work [20].

432 From Fig. 3, it is seen that the OR decreases by increasing the engine load. It is also shown that 433 increasing the engine speed is associated with an increased OR. As can be seen in Fig. 3., at 434 three different engine speeds, there is a strong correlation between fuel exergy and OR, which 435 confirms the strong correlation between fuel exergy and engine load. Increase in load and speed 436 cause an increase in the mass of injected fuel, which increases the fuel exergy. This increase in 437 fuel exergy causes a corresponding increase in the ways by which energy is converted into 438 various forms. Also, from Fig. 3, it is seen that at a specific load and speed, an increase in fuel 439 oxygen content decreases the fuel exergy. This is due to the reduction in LHV of fuels by 440 increasing the oxygen content as discussed before.

442 Load\% (Shape Size): 100(9) - 75(7) - 50(5) - 25 (3) ------- Speed (rpm): $1472(\Delta) 1865$ (O) 2257 (x)

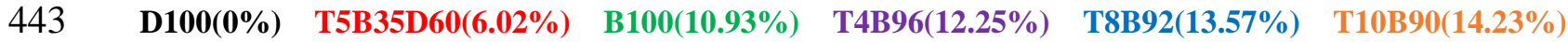

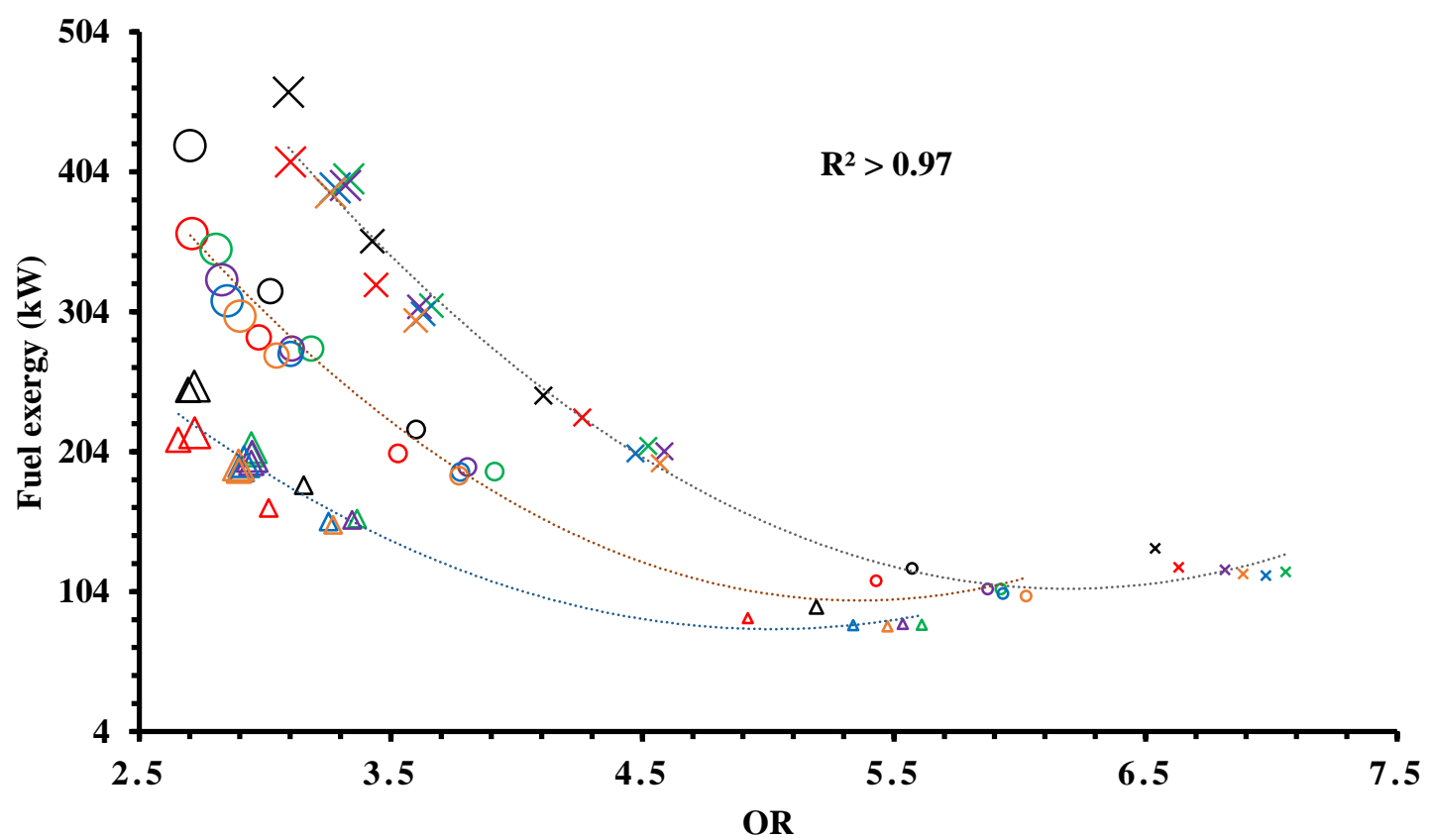

445 Fig. 3. Fuel Exergy vs. OR at 12 engine operating modes for the 6 tested fuels 
447 Brake power is the parameter to present the exergy of the useful work produced by the engine 448 at different speeds and loads for the various fuels is shown in Fig. 4. It is seen that D100 has

449 the highest brake power compared to the oxygenated fuels used at all operating conditions. For 450 the oxygenated fuels, it is seen that the power produced decreases with an increase in oxygen 451 content and is largely attributed to the low heating value of oxygenated fuels. This decrease in 452 heating value of the fuel owing to the increase in oxygen content also significantly influences 453 the fuel energy as shown before. Increasing either the speed or the load causes a corresponding 454 increase in the power produced as more fuel is injected into the chamber, thus increasing the 455 energy input rate.

456

Load\% (Shape Size): 100(9) - 75(7) - 50(5) - 25 (3) ------ Speed (rpm): $1472(\Delta) 1865$ (O) 2257 (x)

458 $\begin{array}{llllll}\text { D100(0\%) } & \text { T5B35D60(6.02\%) } & \text { B100(10.93\%) } & \text { T4B96(12.25\%) } & \text { T8B92(13.57\%) } & \text { T10B90(14.23\%) }\end{array}$

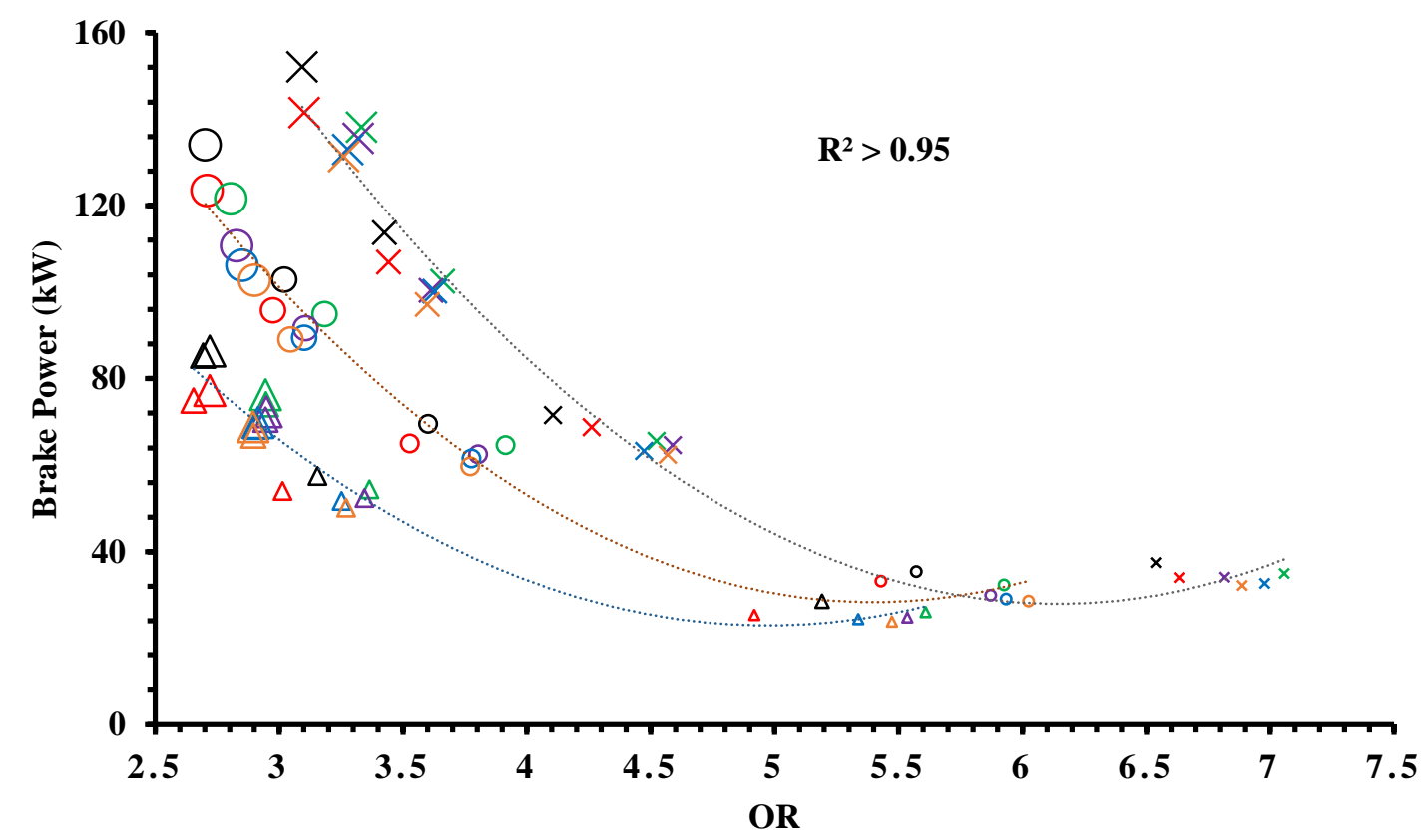

459

460 Fig. 4. Brake power vs. OR at 12 engine operating modes for the 6 tested fuels 461

462 With a fraction of the fuel exergy converted to the brake power, the remaining is lost in varying 463 proportions through the exhaust gas or cooling water losses, or destroyed as a consequence of 
464 a number of irreversible processes, such as mixing, combustion and friction. Considering the

465 fuel exergy lost through the exhaust, Fig. 5 shows the variation of the exhaust exergy loss with

466 OR at different speeds and loads. The effect of increase in speed at a constant load on exhaust

467 exergy loss can clearly been observed in this figure. With the increase in speed, the exhaust

468 exergy loss increases as the time available for complete combustion decreases [40]. This

469 increase in exhaust exergy loss leads to a corresponding decrease in all other fuel exergy values.

470 As the exhaust temperature is the key indication of the exergy loss, a plot of the exhaust exergy

471 against the exhaust temperature is presented in Fig. 6. The fraction of the fuel exergy lost

472 through the exhaust for the different fuels used is seen to follow similar trendlines, as shown

473 in Fig. 6. However, B100 followed a different path and it is represented by a separate trendline.

474 These trendlines, which are polynomials of order 2 , have a very high regression of above 0.99

475 for all speeds. The exhaust exergy loss decreases by decreasing the exhaust gas temperature as

476 shown in this figure. It is seen that increasing the load increases the temperature of the exhaust

477 gas as expected. From the analysis carried out, it is seen that diesel fuel has the highest exhaust

478 exergy loss owing to its high exhaust temperature, at all operating modes [41]. Lower exhaust

479 temperature and exergy loss are seen with oxygenated fuels due to their lower heating values.

480 This indicates a decrease in combustion temperature which has a positive effect on the exhaust

481 exergy loss as it occurs in the lean flame zone [42].

482

483

484

485

486 
487

488

Load\% (Shape Size): 100(9) - 75(7) - 50(5) - 25 (3)

Speed (rpm): $1472(\Delta) 1865$ (O) 2257 (x)

489

$\begin{array}{llllll}\mathrm{D} 100(0 \%) & \mathrm{T} 5 \mathrm{~B} 35 \mathrm{D} 60(6.02 \%) & \mathrm{B} 100(10.93 \%) & \mathrm{T} 4 \mathrm{~B} 96(12.25 \%) & \mathrm{T} 8 \mathrm{~B} 92(13.57 \%) & \mathrm{T} 10 \mathrm{~B} 90(14.23 \%)\end{array}$

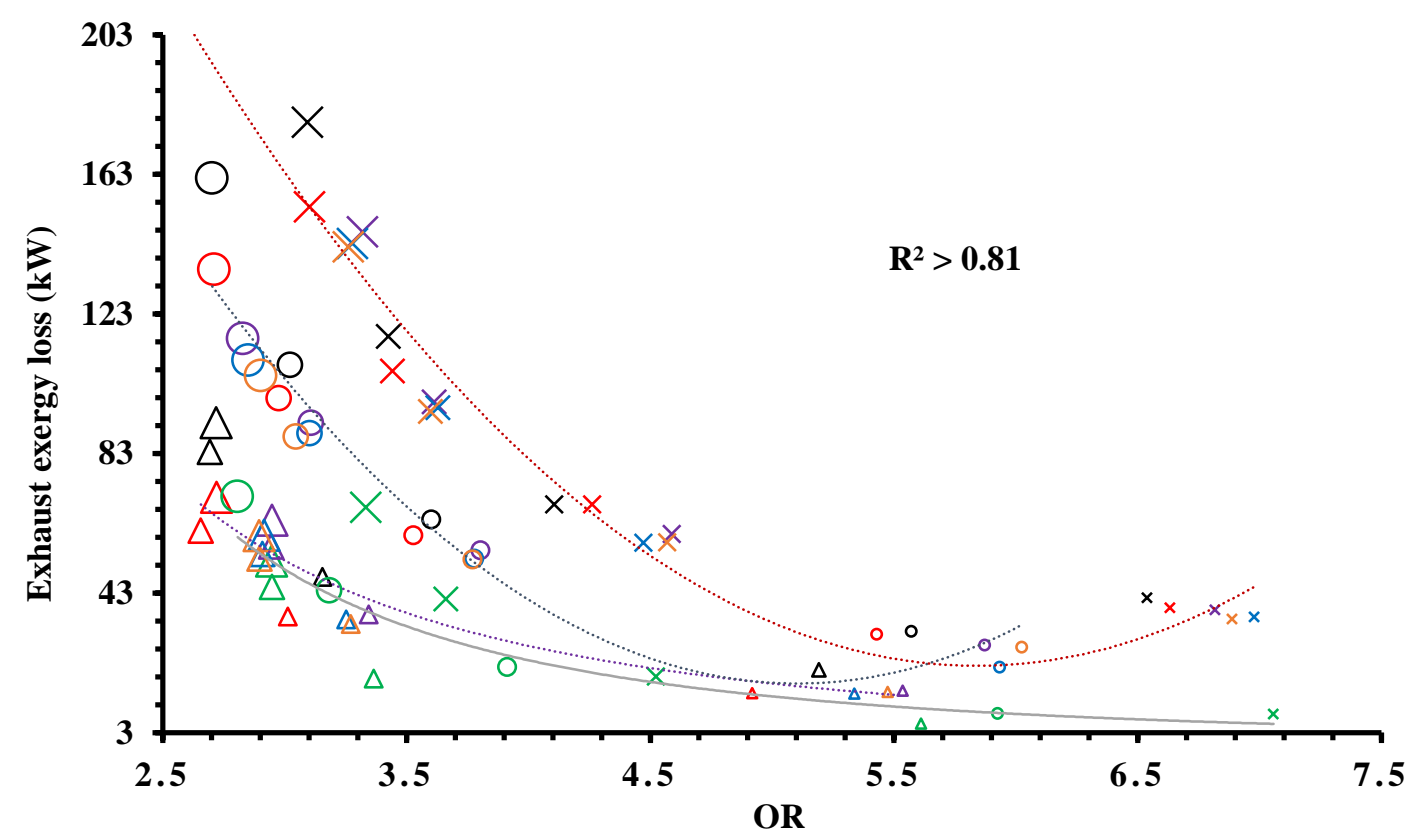

490

491 Fig.5: Exhaust exergy loss vs. OR at 12 engine operating modes for the 6 tested fuels

492

493

Load\% (Shape Size): 100(9) - 75(7) - 50(5) - $25(3)$

Speed (rpm): $1472(\Delta) 1865(0) 2257(x)$

494 $\begin{array}{llllll}\mathrm{D} 100(0 \%) & \mathrm{T} 5 \mathrm{~B} 35 \mathrm{D} 60(6.02 \%) & \mathrm{B} 100(10.93 \%) & \mathrm{T} 4 \mathrm{~B} 96(12.25 \%) & \mathrm{T} 8 \mathrm{~B} 92(13.57 \%) & \mathrm{T} 10 \mathrm{~B} 90(14.23 \%)\end{array}$

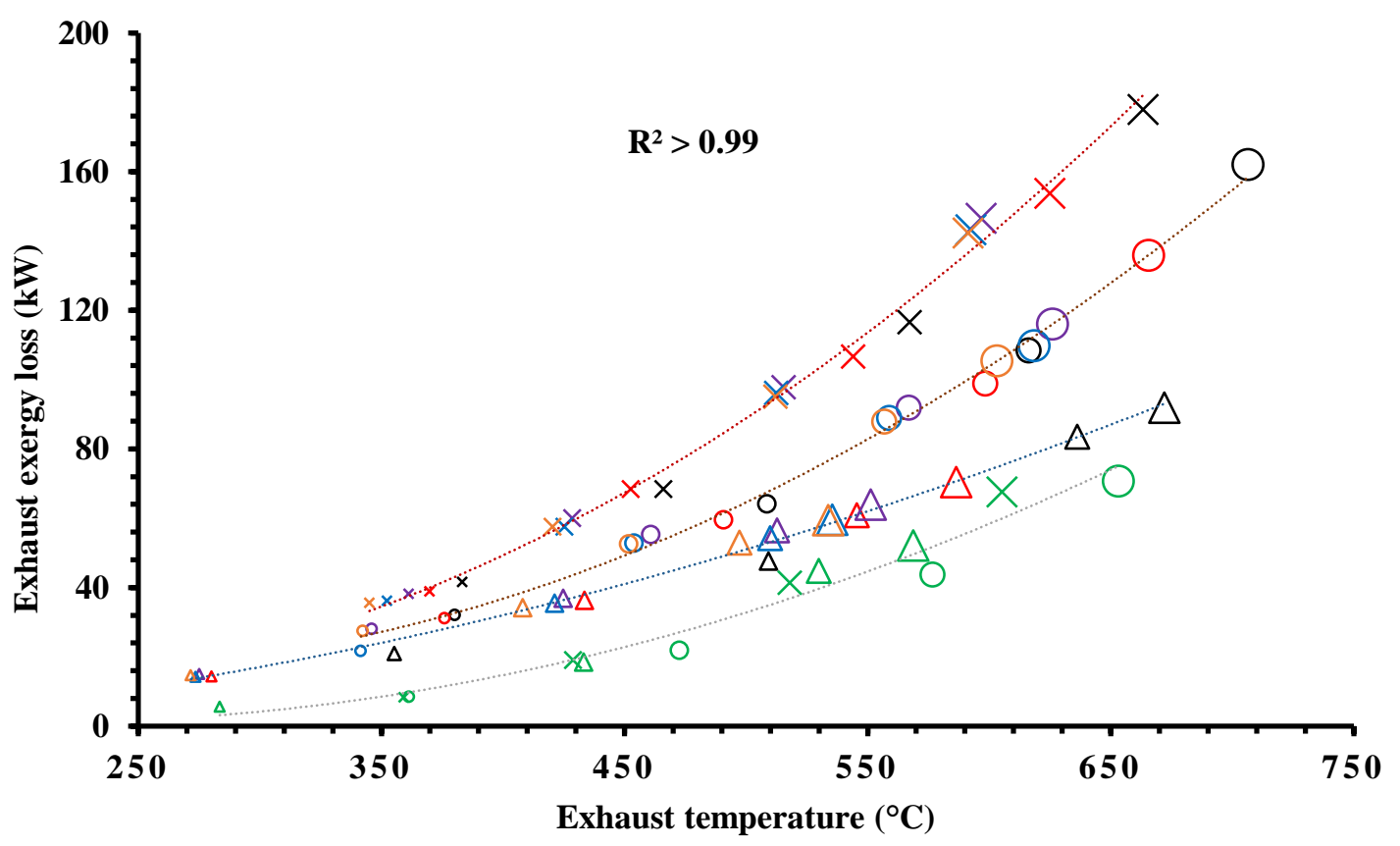

495

496 Fig.6. Exhaust exergy loss vs. exhaust gas temperature at 12 engine operating modes for the 6 497 tested fuels 
498 Factors such as combustion, turbulence, flow losses and mixing are sources of irreversibility 499 and are accounted for as exergy destruction. Since fuel exergy varies with different fuels, 500 exergy destruction ratio, which represents the proportion of fuel exergy destroyed during the 501 combustion, would be an important parameter for comparing different fuels in this study. From

502 Fig. 7, it is seen that the exergy destruction is lower at high loads showing the combustion is 503 happening in condition closer to the ideal with less destruction of exergy. As can be seen, exergy destruction decreases with an increase in both engine load and speed in general.

505 Considering the fuels at all modes, it is seen that the variation in exergy destruction is higher 506 at low loads between the fuels while in high loads all fuels (except B100) are performing more 507 similar. D100 has the lowest destruction ratio and B100 shows the highest destruction ratio at 508 all modes. It is seen that at full load, the lowest destruction is achieved with D100 yielding a destruction ratio of $23.9 \%$, occurring at the highest speed, but with a corresponding high exhaust exergy loss of $38.6 \%$, owing to its high temperature.

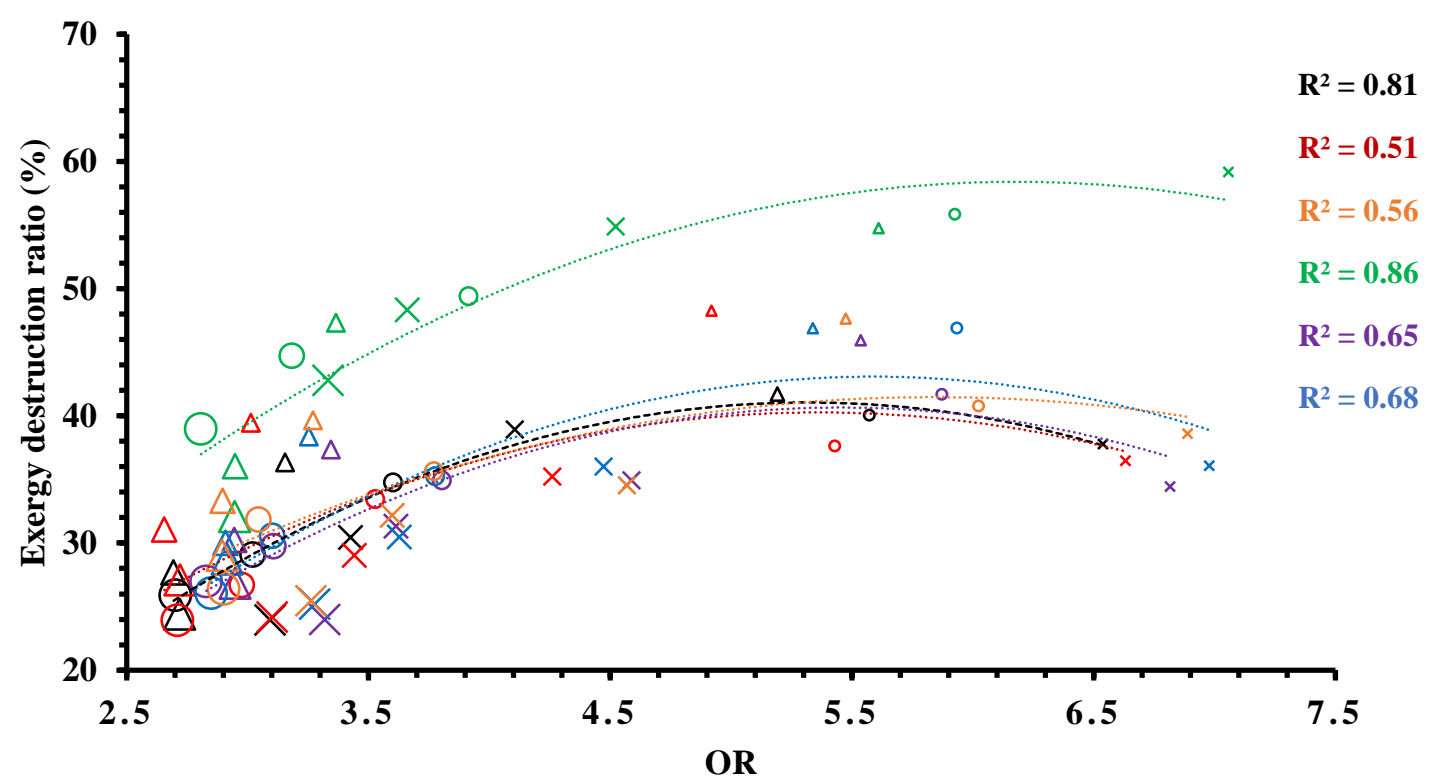


516 As exergy loss and destruction are sometimes interpreted similarly by mistake, they are

517 presented separately in Fig. 8. This figure shows the variation of exergy destruction and the

518 exhaust exergy loss for different fuels at different engine operating modes. A reverse trend

519 between exhaust exergy loss and exergy destruction is found from this figure showing that the

520 parameters affecting exergy destruction are affecting the exergy loss in opposite way. D100

521 maintaining the highest exhaust exergy loss at all operating modes. This is largely attributed to

522 high exhaust gas temperature for diesel as shown before. This is contrary to B100, as the

523 proportion of fuel exergy lost through the exhaust is seen to be the lowest in all operating modes

524 and exergy destruction is the highest. B100 showed a very high destruction and on the other

525 hand a low exergy loss, thus shifting slightly from the path taken by other fuels tested. This

526 fuel exhibits the highest cetane number (lowest ignition delay) meaning the lowest level of premixed combustion with this fuel which leads to more incomplete combustion condition and more exergy destruction. Exergy destruction ratio is seen to be increased with an increase in engine speed with significant reduction in exhaust exergy loss. Also, with load increase, the

530 proportion of the fuel exergy destroyed reduces and a corresponding increase in the exhaust

531 exergy loss is observed. This increase in exhaust exergy loss at increasing load (and also speed)

532 is caused mainly by the increase in temperature at which the gases leave the combustion 533 chamber. 


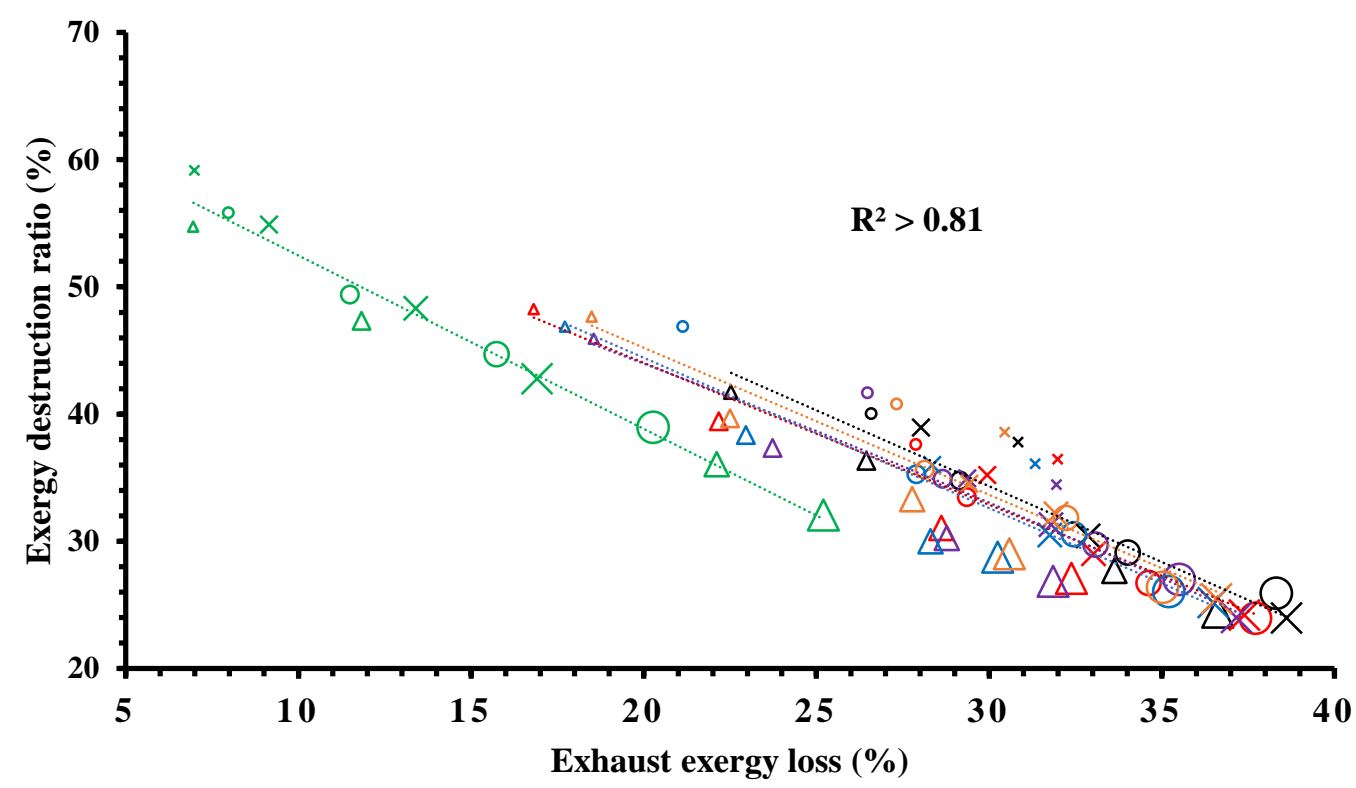

542

543

544

545

546

547

548

549

550

551

552

553

554

555

556

Fig. 8. Exergy destruction ratio vs. Exhaust exergy loss at 12 engine operating modes for the 6 tested fuels

Fig. 9 shows the exergetic efficiency, which defined as the ratio of brake power to the fuel exergy, for different conditions. The proportion of extracted useful work is seen to be increased with an increase in load and the maximum values happen at the lowest speed and $100 \%$ load for all the fuels. This is similar to its energy counterpart, but has a lower efficiency, whose percentage difference with the BTE ranges from $6.56 \%$ for D100 and increases with an increase in oxygen content to $7.02 \%$ in T10B90. The exergetic efficiency gives a better idea of engine operation as it takes into account both the first and second laws of thermodynamics as well as the exergy destructions and exergy losses. At a constant load, the exergetic efficiency is seen to be decreased by increasing speed causing the minimum exergetic efficiency to be seen at $25 \%$ load operated at $2257 \mathrm{rpm}$. This is attributed to the decrease in volumetric efficiency of the combustion chamber as less time is required to fill the cylinder [43]. 
557 The other important finding is the exergetic efficiency improvement with the use of oxygenated

558 fuels, with the exception at $25 \%$ load. This increase in exergetic efficiency is primarily due to

559 the better combustion of these oxygenated fuels and less losses, compared to D100. The highest

560 exergetic efficiency is exhibited by B100 at all operating modes, and thus can be considered a

561 better quality fuel than other fuels used, if we assume the exergetic efficiency as the measure

562 of fuel quality. At low loads, the lower exergetic efficiency was observed by some of the

563 oxygenated fuels (T4B96, T8B92 and T10B90) when compared with D100. It could be

564 attributed to low in-cylinder pressure and also low combustion temperature, as an increase in

565 load provides an appropriate condition for combustion for this fuels [43]. This is seen to be

566 reversed with an increase in load, as higher combustion temperatures with the oxygenated fuels

567 were obtained, thus converting more heat into useful work.

568

569

Load\% (Shape Size): 100(9) - 75(7) - 50(5) - 25 (3) ------ Speed (rpm): $1472(\Delta) 1865$ (O) 2257 (x)

570

$\begin{array}{llllll}\mathrm{D} 100(0 \%) & \mathrm{T} 5 \mathrm{~B} 35 \mathrm{D} 60(6.02 \%) & \mathrm{B} 100(10.93 \%) & \mathrm{T} 4 \mathrm{~B} 96(12.25 \%) & \mathrm{T} 8 \mathrm{~B} 92(13.57 \%) & \mathrm{T} 10 \mathrm{~B} 90(14.23 \%)\end{array}$

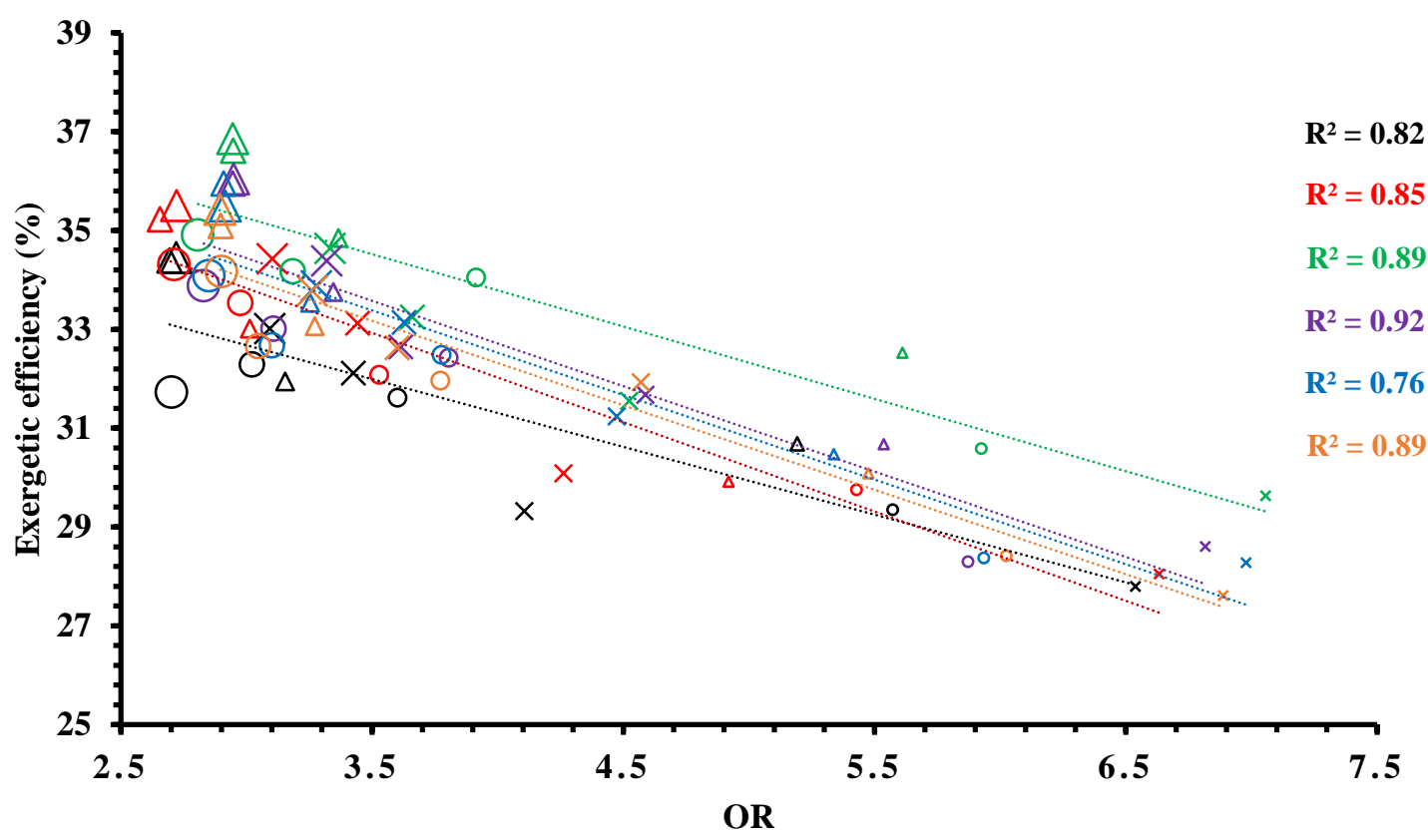

571

572 Fig. 9. Exergetic efficiency at 12 engine operating modes for the 6 tested fuels 
575 The correlation between exergetic efficiency and BSFC for fuels at different speeds and loads

576 shows a linear trend and is presented in Fig. 10. Considering the BSFC, it is seen that at all 577 three speeds, by increasing the engine load the BSFC reduces and the minimum BSFC was 578 obtained at full load. Also, at any given load, an increase in speed causes an increase in BSFC.

579 As can be seen, the BSFC increases with an increase in oxygen content. This is because an 580 increase in the oxygen content of the fuel causes a decrease in the lower heating value [44].

581 The oxygen content of the fuel is a good indicator of the loss of heating value and increased 582 fuel consumption [39]. It is seen that D100 had the lowest BSFC at all modes, owing to its high 583 heating value. The minimum BSFC was $0.22 \mathrm{~g} / \mathrm{kWh}$ at full load and $1475 \mathrm{rpm}$ belongs to D100, 584 while the maximum BSFC was observed at $0.342 \mathrm{~g} / \mathrm{kWh}$ with the higher oxygenated fuel 585 (T10B90) operating at 25\% load and $2257 \mathrm{rpm}$.

586 Considering BSFC against exergetic efficiency, maximum exergetic efficiency can deliver the 587 lowest BSFC. Values of BSFC decrease with decreasing speed and increasing load, causing a 588 corresponding increase in the exergetic efficiency and operating the engine at low speed (1472 589 rpm) and high load yields the lowest possible BSFC and the highest exergetic efficiency for each individual fuel considered. It is seen that D100 has the lowest BSFC and exergetic

591 efficiency, while B100 shows the highest exergetic efficiency with moderate BSFC. As can be 592 seen, maximum exergetic efficiency is for B100 and addition of triacetin to biodiesel (which 593 results in a lower heating value) increases the BSFC and decreases the exergetic efficiency [20].

594 From the plot the increase in diesel content of the oxygenated fuel, causes a decrease in BSFC, 595 as observed for T5B35D60. 


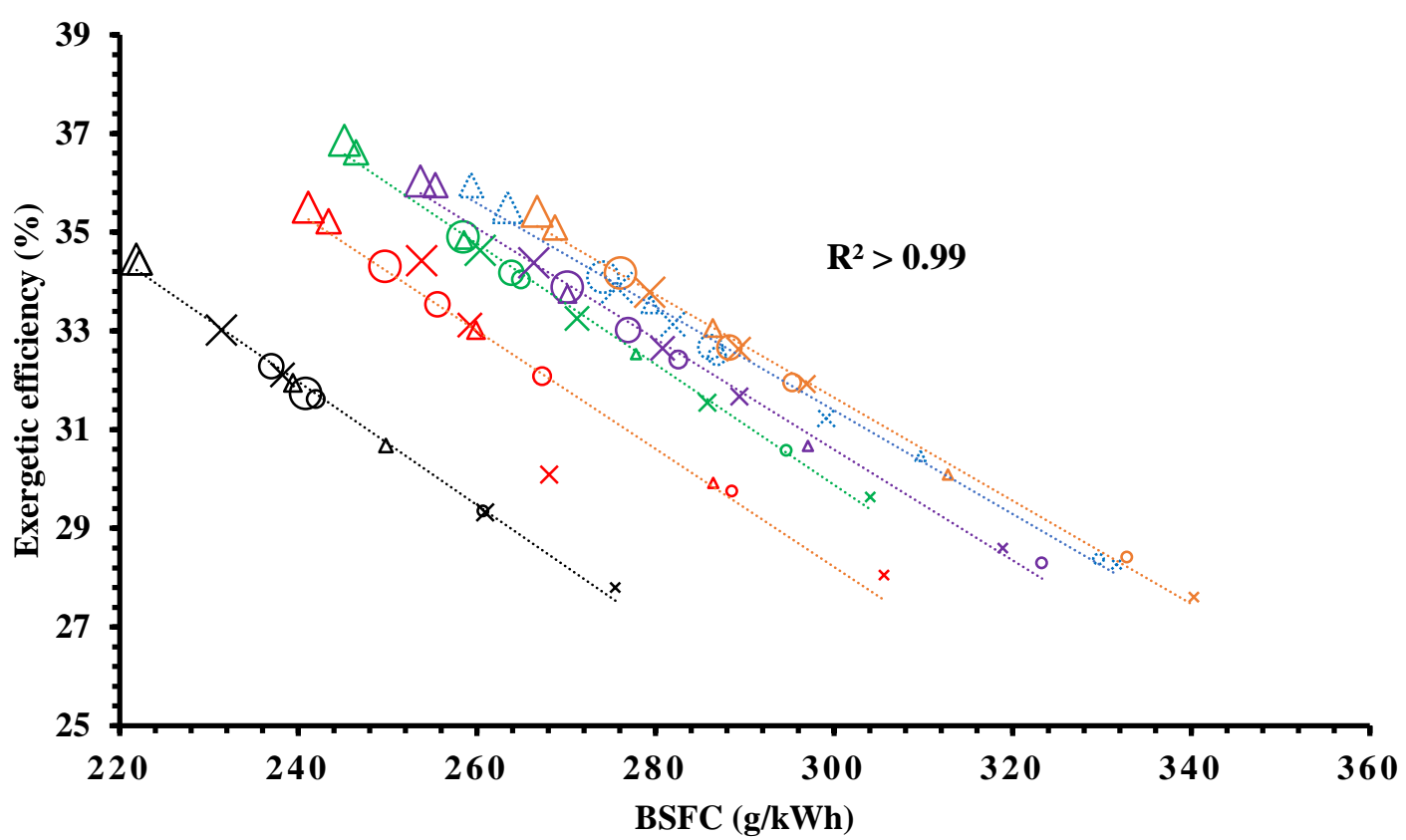

600

601 Fig.10. Exergetic Efficiency vs. BSFC at 12 engine operating modes for the 6 tested fuels

602

603 As the LHV is different for the fuels used in this study, $B S F C_{\text {equivalent }}$ is calculated to develop

604 a further analysis of the results presented in Fig. 11. Equivalent brake specific fuel consumption

$605 B S F C_{\text {equivalent }}$ represents the amount of diesel fuel equivalent for producing the same amount of power and it is defined as follow [45]:

607

$$
B S F C_{\text {equivalent }}=B S F C \times L H V_{\text {blend }} / L H V_{\text {diesel }}
$$

608 The results of exergetic efficiency vs. $B S F C_{\text {equivalent }}$ are presented in Figure 11 . All the 609 biofuels are following almost the same trendlines, however, the trend is still similar to Figure 610 10. As can be seen, improving the exergetic efficiency means achieving lower $B S F C_{\text {equivalent }}$ 611 for each fuel as presented on this figure. Among all the tested fuels, the $B S F C_{\text {equivalent }}$ for 612 B100 is the lowest at different operating conditions making it a better alternative fuel. At low 613 load and high speed, the $B S F C_{\text {equivalent }}$ of all the tested fuels are higher than diesel (except 614 for B100). This trend changes by increasing the load and speed for different fuels. 


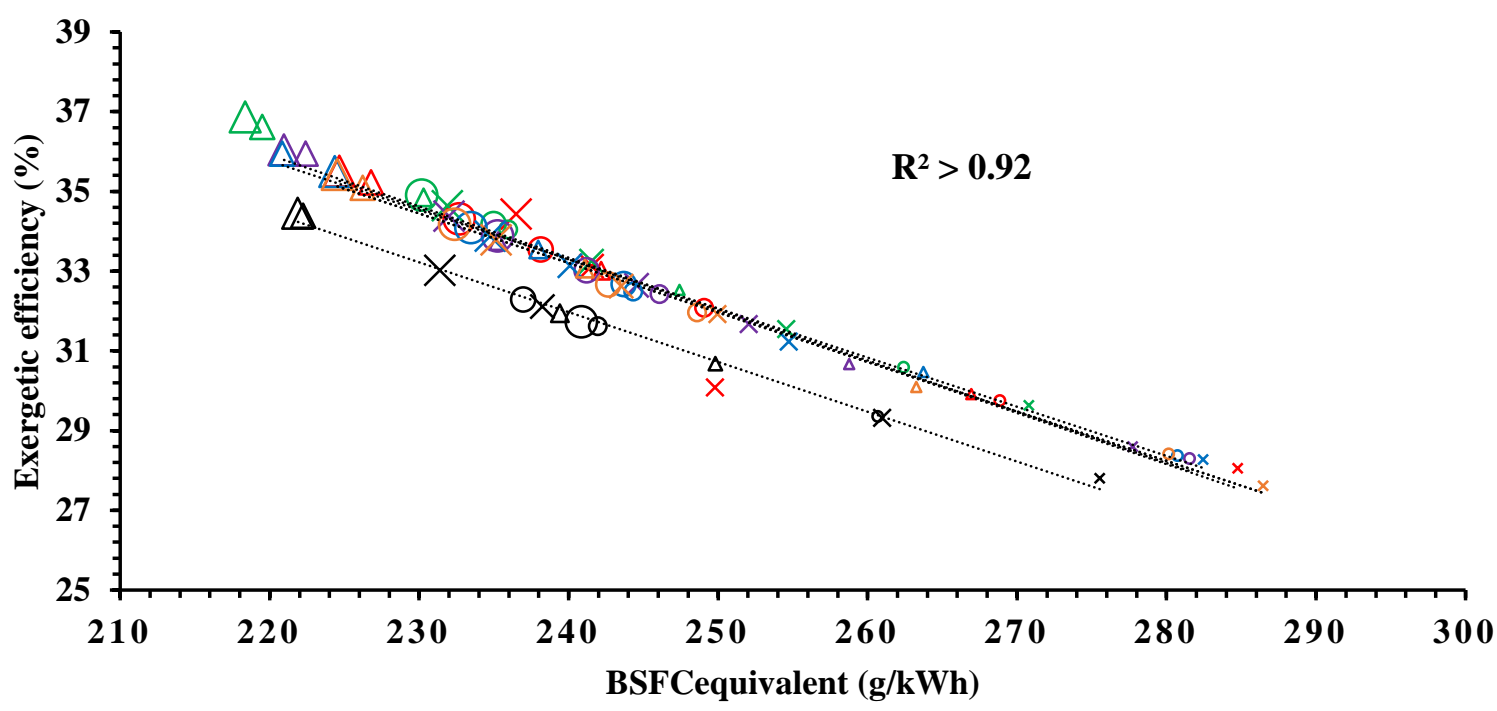

618 Fig.11. Exergetic Efficiency vs. BSFCequivalent at 12 engine operating modes for the 6 619 tested fuels

620

621 A linear trend can be obtained when the BTE is plotted against the exergetic efficiency in Fig. 12. This is because the BTE and exergetic efficiency are both used to measure the quantity of

623 the heat converted to work with respect to first and second law analysis. Comparing the exergetic efficiency against BTE, it is seen that the BTE is higher for all operating conditions than the exergetic efficiency owing to the lower value of energy input rate when compared to the high chemical exergy of the fuel used in the exergy analysis. Also, the exergetic efficiency combines both first and second law efficiency to account for the usefulness of the energy being supplied.

From both efficiencies, it is seen that they depend on the lower heating value of the fuel. The

630 lower heating value of D100 is seen to be the highest, and decreases with an increase in fuel

631 oxygen content while T10B90 has the lowest heating value. From Fig. 12, it is seen that D100

632 clearly distinguishes itself from the other fuels owing to the low fuel consumption and high 633 heating value (minimum difference with the oxygenated fuels used in this study is 
634 approximately $4800 \mathrm{~kJ} / \mathrm{kg}$ ). This high heating value of D100, which produces less power with 635 respect to the energy input, causes a visible decrease in the exergetic efficiency of the diesel 636 fuel as it moves below the other fuels' line. It is also seen that the oxygenated fuels are closely 637 packed and increase linearly. This cluster is mainly attributed to the closeness of their 638 respective heating value and fuel consumption. With respect to oxygenated fuels, it is seen that 639 T10B90 (with the lowest heating value) had the lowest BTE and exergetic efficiency.

640

641

Load\% (Shape Size): 100(9) - 75(7) - 50(5) - 25 (3) ------- Speed (rpm): $1472(\Delta) 1865$ (O) 2257 (x)

642

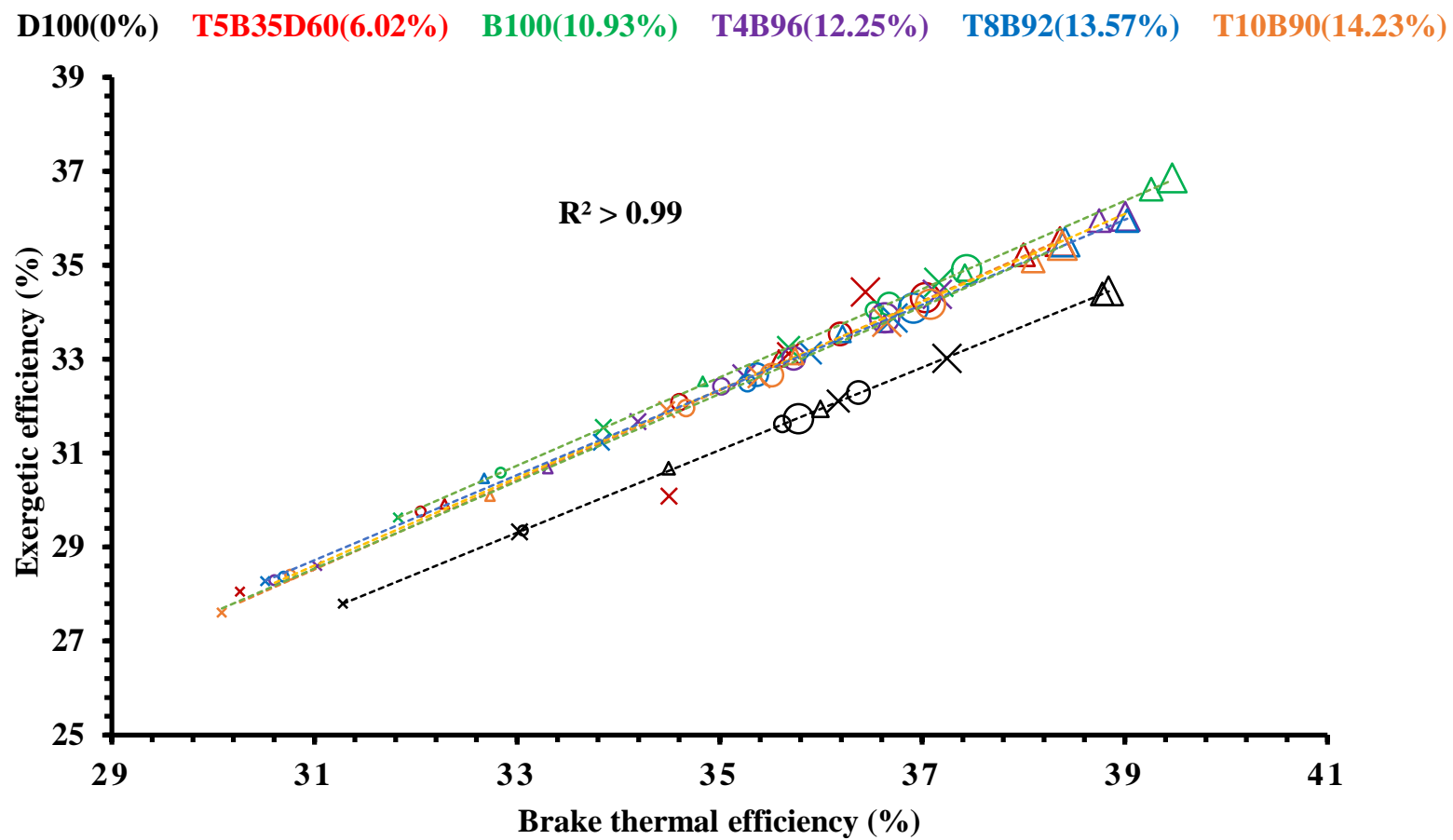

643

644 Fig. 12: Exergetic Efficiency vs. Brake thermal efficiency at 12 engine operating modes for 645 the 6 tested fuels

646

647 4. Conclusion

648 This investigation used the first and second laws of thermodynamics to analyse the influence 649 of oxygenated fuels on the quality and quantity of energy in a diesel engine using diesel, waste 650 cooking biodiesel, and a highly oxygenated additive, triacetin. The six fuels used in this study 
had a range of fuel oxygen content from 0 to $14 \mathrm{wt} \%$. The experimental engine performance and emission data were collected at 12 different engine operating modes (three different speeds and four engine loads), and were used to calculate and analyse the energy and exergy

654 parameters, such as: fuel energy, thermal efficiency, exhaust energy loss, exergetic efficiency, 655 destruction efficiency and exhaust exergy. The following conclusions were obtained from this 656 study:

- Since the investigated fuels were oxygenated, this study used the oxygen ratio (OR) instead of the equivalence ratio.

- OR increased with decreasing engine load and increasing engine speed.

- OR showed strong correlations (with a high $\mathrm{R}^{2}$ ) for different energy and exergy parameters.

- Increasing the OR decreased the fuel exergy, exhaust exergy, destruction efficiency and exergetic efficiency, while it increased the exergy destruction.

- Strong correlations with high $\mathrm{R}^{2}$ was found between exhaust energy loss and brake thermal efficiency, exhaust exergy and exhaust temperature, destruction efficiency and

- Using oxygenated fuels resulted in higher brake thermal efficiency, OR, exergy destruction and exergetic efficiency; and lower exhaust energy loss, fuel exergy, engine power, exhaust exergy, exhaust temperature and brake specific fuel consumption. to be reduced with the addition of triacetin, but with a corresponding loss in heating value.

- Lower exhaust temperature obtained with oxygenated fuels resulted in lower exhaust exergy losses and higher exergetic efficiency. 
677 The authors would like to thank Professor Zoran Ristovski, Dr Mostafizur Rahman, Dr Farhad

678 Hossein and Mr. Noel Hartnett from QUT and Mr Andrew Elder from DynoLog Dynamometer

679 Pty Ltd. for their help in this research.

680

References

682

683

684

685

686

687

688

689

690

691

692

693

694

695

696

697

698

699

700

701

702

703

704

[1] R.E. Ebel, M.P. Croissant, J.R. Masih, K.E. Calder, R.G. Thomas. International energy outlook: US Department of Energy. Washington Quarterly. 19 (1996) 70-99.

[2] A. Demirbaş. Biodiesel fuels from vegetable oils via catalytic and non-catalytic supercritical alcohol transesterifications and other methods: a survey. Energy conversion and Management. 44 (2003) 2093-109.

[3] K. Cheikh, A. Sary, L. Khaled, L. Abdelkrim, T. Mohand. Experimental assessment of performance and emissions maps for biodiesel fueled compression ignition engine. Applied Energy. 161 (2016) 320-9.

[4] M. Rahman, A. Pourkhesalian, M. Jahirul, S. Stevanovic, P. Pham, H. Wang, et al. Particle emissions from biodiesels with different physical properties and chemical composition. Fuel. 134 (2014) 201-8.

[5] H. Omidvarborna, A. Kumar, D.-S. Kim. A laboratory investigation on the effects of unsaturated bonds and chain lengths of different biodiesel feedstocks on carbon dioxide, carbon monoxide, and methane emissions under low-temperature combustion. Journal of Environmental Chemical Engineering. 4 (2016) 4769-75.

[6] A. Manikandan. Application of Exergy (Availability) Analysis to Spark-Ignition Engines Operation Considering a Single-Zone Combustion Model. Proceedings of National Conf on Recent Innovations in Science Engineering \& Technology, Pune, 2014.

[7] M.A. Rosen. Exergy concept and its application. Electrical Power Conference, 2007 EPC 2007 IEEE Canada. IEEE2007. pp. 473-8.

[8] Y. Li, M. Jia, Y. Chang, S.L. Kokjohn, R.D. Reitz. Thermodynamic energy and exergy analysis of three different engine combustion regimes. Applied Energy. 180 (2016) 849-58.

[9] M. Chahartaghi, M. Sheykhi. Energy and exergy analyses of beta-type Stirling engine at different working conditions. Energy Conversion and Management. 169 (2018) 279-90.

[10] J.A. Caton. The thermodynamic characteristics of high efficiency, internal-combustion engines. Energy Conversion and Management. 58 (2012) 84-93.

[11] M. Nabi, M. Rasul. Influence of second generation biodiesel on engine performance, emissions, energy and exergy parameters. Energy Conversion and Management. 169 (2018) 326-33.

[12] E.J. Cavalcanti, M. Carvalho, A.A. Ochoa. Exergoeconomic and exergoenvironmental comparison of diesel-biodiesel blends in a direct injection engine at variable loads. Energy Conversion and Management. 183 (2019) 450-61.

[13] H. Feng, X. Wang, J. Zhang. Study on the effects of intake conditions on the exergy destruction of low temperature combustion engine for a toluene reference fuel. Energy Conversion and Management. 188 (2019) 241-9. 
[14] A. Karthikeyan, J. Jayaprabakar. Energy and exergy analysis of compression ignition engine fuelled with rice bran biodiesel blends. International Journal of Ambient Energy. 40 (2019) 381-7.

[15] C. Rakopoulos, E. Giakoumis. Simulation and exergy analysis of transient diesel-engine operation. Energy. 22 (1997) 875-85.

[16] E. Hürdoğan. Thermodynamic analysis of a diesel engine fueled with diesel and peanut biodiesel. Environmental Progress \& Sustainable Energy. 35 (2016) 891-7. [17] S. Jafarmadar, P. Nemati. Exergy analysis of diesel/biodiesel combustion in a homogenous charge compression ignition ( $\mathrm{HCCI}$ ) engine using three-dimensional model. Renewable Energy. 99 (2016) 514-23. [18] F. Meisami, H. Ajam. Energy, exergy and economic analysis of a Diesel engine fueled with castor oil biodiesel. International Journal of Engine Research. 16 (2015) 691-702.

[19] B. Sayin Kul, A. Kahraman. Energy and Exergy Analyses of a Diesel Engine Fuelled with Biodiesel-Diesel Blends Containing 5\% Bioethanol. Entropy. 18 (2016) 387. [20] A. Zare, M.N. Nabi, T.A. Bodisco, F.M. Hossain, M.M. Rahman, Z.D. Ristovski, et al. The effect of triacetin as a fuel additive to waste cooking biodiesel on engine performance and exhaust emissions. Fuel. 182 (2016) 640-9.

[21] A. Zare, T.A. Bodisco, M.N. Nabi, F.M. Hossain, M. Rahman, Z.D. Ristovski, et al. The influence of oxygenated fuels on transient and steady-state engine emissions. Energy. 121 (2017) 841-53.

[22] M.N. Nabi, A. Zare, F.M. Hossain, M.M. Rahman, T.A. Bodisco, Z.D. Ristovski, et al. Influence of fuel-borne oxygen on European Stationary Cycle: Diesel engine performance and emissions with a special emphasis on particulate and NO emissions. Energy conversion and management. 127 (2016) 187-98.

[23] H. Song, K.S. Quinton, Z. Peng, H. Zhao, N. Ladommatos. Effects of oxygen content of fuels on combustion and emissions of diesel engines. Energies. 9 (2016) 28.

[24] J. Jena, R.D. Misra. Effect of fuel oxygen on the energetic and exergetic efficiency of a compression ignition engine fuelled separately with palm and karanja biodiesels. Energy. 68 (2014) 411-9.

[25] M. Nour, A.M. Attia, S.A. Nada. Combustion, performance and emission analysis of diesel engine fuelled by higher alcohols (butanol, octanol and heptanol)/diesel blends. Energy Conversion and Management. 185 (2019) 313-29.

[26] Z. Han, B. Li, W. Tian, Q. Xia, S. Leng. Influence of coupling action of oxygenated fuel and gas circuit oxygen on hydrocarbons formation in diesel engine. Energy. 173 (2019) 196206.

[27] H. Sayyaadi, M. Babaie, M.R. Farmani. Implementing of the multi-objective particle swarm optimizer and fuzzy decision-maker in exergetic, exergoeconomic and environmental optimization of a benchmark cogeneration system. Energy. 36 (2011) 4777-89.

[28] H. Sayyaadi, M. Baghsheikhi, M. Babaie. Improvement of energy systems using the soft computing techniques. International Journal of Exergy. 19 (2016) 315-51.

[29] A. Zare, T.A. Bodisco, M.N. Nabi, F.M. Hossain, Z.D. Ristovski, R.J. Brown. Engine performance during transient and steady-state operation with oxygenated fuels. Energy \& fuels. 31 (2017) 7510-22.

[30] A. Zare, M.N. Nabi, T.A. Bodisco, F.M. Hossain, M. Rahman, T.C. Van, et al. Diesel engine emissions with oxygenated fuels: A comparative study into cold-start and hot-start operation. Journal of cleaner production. 162 (2017) 997-1008.

[31] S. van Dyk, J. Su, J.D. Mcmillan, J. Saddler. Potential synergies of drop -in biofuel production with further co-processing at oil refineries. Biofuels, Bioproducts and Biorefining.

$76513(2019) 760-75$. 

acid methyl ester profiles on inter-cycle variability in a heavy duty compression ignition engine. Fuel. 116 (2014) 140-50. [33] C. Sayin, M. Hosoz, M. Canakci, I. Kilicaslan. Energy and exergy analyses of a gasoline engine. International Journal of Energy Research. 31 (2007) 259-73. [34] R.E. Sonntag, C. Borgnakke, G.J. Van Wylen, S. Van Wyk. Fundamentals of thermodynamics. Wiley New York2003. [35] T. Kotas. The Exergy Method of Thermal Plant Analysis. Reprint Edition. Krieger Malabar,Florida, 1995. [36] S. Fateh. Bi-directional Solid Oxide Cells used as SOFC for Aircraft APU system and as SOEC to produce fuel at the airport. (2016). [37] E. Querol, B. Gonzalez-Regueral, J.L. Perez-Benedito. Practical approach to exergy and thermoeconomic analyses of industrial processes. Springer Science \& Business Media2012. [38] M.J. Moran, H.N. Shapiro, D.D. Boettner, M.B. Bailey. Fundamentals of engineering thermodynamics. John Wiley \& Sons 2010. [39] P. Sekmen, Z. Yılbaş1. Application of energy and exergy analyses to a CI engine using biodiesel fuel. Mathematical and Computational Applications. 16 (2011) 797-808. [40] M. Ghazikhani, M. Hatami, B. Safari, D.D. Ganji. Experimental investigation of exhaust temperature and delivery ratio effect on emissions and performance of a gasoline-ethanol twostroke engine. Case Studies in Thermal Engineering. 2 (2014) 82-90.

786 [41] X. Liu, R. Bansal. Thermal Power Plants: Modeling, Control, and Efficiency Improvement. 787 CRC Press2016.

788 [42] Y.H. Tan, M.O. Abdullah, C. Nolasco-Hipolito, N.S.A. Zauzi, G.W. Abdullah. Engine performance and emissions characteristics of a diesel engine fueled with diesel-biodieselbioethanol emulsions. Energy Conversion and Management. 132 (2017) 54-64. [43] G. Khoobbakht, A. Akram, M. Karimi, G. Najafi. Exergy and energy analysis of combustion of blended levels of biodiesel, ethanol and diesel fuel in a DI diesel engine. Applied Thermal Engineering. 99 (2016) 720-9.

794 [44] A. Fayyazbakhsh, V. Pirouzfar. Comprehensive overview on diesel additives to reduce 795 emissions, enhance fuel properties and improve engine performance. Renewable and 796 Sustainable Energy Reviews. 74 (2017) 891-901.

797 [45] G. Chen, Y. Shen, Q. Zhang, M. Yao, Z. Zheng, H. Liu. Experimental study on combustion 798 and emission characteristics of a diesel engine fueled with 2, 5-dimethylfuran-diesel, n799 butanol-diesel and gasoline-diesel blends. Energy. 54 (2013) 333-42. 